\title{
THE DISSOCIATION BETWEEN NOUNS AND VERBS IN BROCA'S AND WERNICKE'S APHASIA: FINDINGS FROM CHINESE
}

\author{
Sylvia Chen \\ University of Southern California \\ Elizabeth Bates \\ University of California, San Diego
}

Aphasiology, 1998, 12(1), 5-36.

Please send correspondence to: Elizabeth Bates, Center for Research in Language 0526, University of California, San Diego, 9500 Gilman Drive, La Jolla, CA 92093-0526.

Phone: 619-534-6070; Fax: 619-534-6788. 


\title{
THE DISSOCIATION BETWEEN NOUNS AND VERBS IN BROCA'S AND WERNICKE'S APHASIA: FINDINGS FROM CHINESE
}

\author{
Sylvia Chen and Elizabeth Bates
}

\begin{abstract}
Studies in English and Italian have shown that non-fluent Broca's aphasics find it more difficult to produce verbs than nouns, while some fluent patients (including Wernicke's aphasics and anomics) show the opposite profile. Explanations for this double dissociation include grammatical accounts (e.g. verb deficits reflect differences in morphological and/or syntactic complexity), semantic-conceptual accounts (e.g. verbs are based on action meanings, which are stored in anterior motor regions; nouns are based on object meanings, which are stored in sensory cortex), and lexical accounts (verbs and nouns are stored in separate regions of the brain, independent of their semantic content). In Chinese, many words are compounds with a complex internal structure, including VN compound verbs like 'LOOK-BOOK' ('read') and VN compound nouns like 'STAND-GOOSE' ('penguin'. Hence words may be nouns at the lexical level, but they contain verbal elements at the sublexical level, providing a challenge to existing explanations for the noun-verb dissociation. An object- and action-naming study was conducted with Chinese Broca's and Wernicke's aphasics, designed to elicit several different compound types (VN nouns, VN verbs, VNN nouns, NNN nouns and $\mathrm{NN}$ nouns). We replicate the noun-verb double dissociation at the whole-word level, and provide further evidence for a double dissociation at the sublexical level: Broca's err more often on the verb morpheme within VN nouns as well as VN verbs; Wernicke's err more often on noun morphemes, and they often produce verb morphemes where none are required (e.g. substituting VV for NN words). Hence explanations for the noun-verb dissociation must apply at both the lexical and the sublexical level, a problem for all current accounts.
\end{abstract}

\section{Introduction}

One of the most puzzling dissociations in the literature on language breakdown in aphasia is the apparent double dissociation between nouns and verbs (Berndt and Zingeser 1991; Goodglass 1993; Caramazza and Hillis 1991; Glosser et al. 1994; Joanette and Brownell 1990; Zingeser and Berndt 1990). Several studies have reported that Broca's aphasics display specific deficits in the production of main verbs, compared with their production of object names. These patients often omit verbs in their spontaneous speech. For example, the verb 'to give' is omitted in the description 'The girl is ... the flower' for a picture in which a girl is giving flowers to a woman. Alternatively, they sometimes replace verbs with a corresponding nominal form, e.g. the use of 'Bunny ... tears' for a picture that normals describe with 'Bunny cries' (examples from Bates et al. 1988). A complementary profile has been reported for fluent patients, including Wernicke's aphasics and some anomics. These patients display fewer problems with verbs and more severe problems in the production of names for common objects in their spontaneous speech, resulting in an overuse of pronominal forms and circumlocutionary frames (e.g. 'This thing here, whatever it is called, it's crying'-from Bates et al. 1991a), and in the production of semantic paraphasias (e.g. 'Baguette' instead of 'Bunny'-Bates et al. 1988), and (in more severe cases) neologisms and jargon.

The noun-verb dissociation was originally reported for spontaneous speech, but it has also been observed in experimental studies of object and action naming outside of a sentence context (Miceli et al. 1984; OsmánSági 1987). Specifically, when some non-fluent and fluent aphasics are asked to name simple objects and actions, they show opposite patterns of naming difficulty: Broca's aphasics make more errors on action- naming items, while Wernicke's and/or anomics make more errors in object naming.

This peculiar double dissociation seems to have been forced upon us by the empirical facts. It does not follow naturally from any particular linguistic theory (but see Zingeser and Berndt 1990). Indeed, Caplan (1987) has proposed that we might be well advised to leave this phenomenon out of linguistically motivated theories of agrammatism:

We may exclude any problems with main verbs from agrammatism, for the following reasons..... As we have seen, there are several possible characterizations of the affected elements within one or another version of linguistic theory and psycholinguistic processing models. These formulations all identify sets of affected language elements, and also exclude certain language elements from these sets.....Verbs are excluded from these sets of vocabulary elements. Therefore, abnormalities affecting verb roots, such as their absence of replacement by nominal stems, are not part of the agrammatic features of speech, but have some other source. It is, of course, possible that other formal characterizations would group the elements designated in these theories together with verbs, but to date no such characterizations has been stated...Variation in this aspects of the speech of agrammatic patients, though interesting, does not affected our ability to define agrammatism (p. 284).

Caplan's advice notwithstanding, the robust and persistent double dissociation between nouns and verbs has driven some investigators to search for some kind of grammatical, semantic or conceptual explanation. At least four explanations have been offered (see Bates et al. 1991a, 1993). In the first two cases, verb deficits in Broca's aphasia are viewed as a by-product of agram- 
matism. In the second two cases, the deficit is located outside the grammar, at a lexical and/or conceptual level.

1. The morphological account. This model traces the noun/verb dissociation to problems at the level of grammatical morphology (Caramazza and Berndt 1985). Specifically, it has been argued that the presence of verb problems in Broca's aphasia reflects a more general deficit that these patients display in the use of grammatical inflections. Because verbs carry a heavier load of grammatical markings than nouns, Broca's aphasics, who suffer from grammatical impairment, are less capable of producing verbs.

2. The syntactic account. The second model also approaches the main-verb problem in Broca's aphasia as a kind of grammatical impairment, but in this case the deficit is attributed to the greater syntactic complexity of verbs. In particular, verbs are syntactically more complex than nouns because verbs determine the number of arguments in a sentence; nouns are used to fill these arguments, but they do not assign them (Lapointe 1985). A variant of this argument can be found in Joanette and Brownell (1990), who suggest that a deficit in main verbs may be only one manifestation of a more general problem with predication.

3. The semantic-conceptual account. In this model, noun-verb dissociations are attributed to contrasting impairments at the semantic-conceptual level. This claim is compatible with the idea that the anterior (motor) cortex participates in the activation of action meaning while the posterior (sensory) cortex plays a greater role in object meaning (Petersen et al. 1988, Damasio 1989).

4. The lexical account. The fourth and final explanation is that the noun-verb dissociation observed in fluent and nonfluent aphasics reflects a breakdown in processing that is located entirely within the lexicon (Miceli et al. 1984, 1988; see also Caramazza and Hillis (1991). More precisely, Miceli et al. have argued that nouns and verbs are stored in separate regions within the mental lexicon. The noun-verb dissociation in aphasia reflects selective damage at the lexical level, a claim that is independent of the grammatical and/or semanticconceptual roles that these lexical items carry. More detailed variants of this model provide even more distinctions. For example, to account for the fact that some patients show the noun-verb dissociation only in production while others show it only in comprehension, Miceli et al. (1988) have proposed four separate lexicons: a noun input lexicon, a verb input lexicon, a noun output lexicon, and a verb output lexicon. In the same vein, Caramazza and Hillis (1991) and Hillis and Caramazza (1994) have described cases that show these form class dissociations only in speaking, or in writing. They have thus proposed separate lexicons for nouns versus verbs in each modality (see also Berndt and Zingeser 1991).

There are a number of problems with these explanations. The first problem has to do with the causal asymmetry of the two grammatical accounts (morphological and syntactic). Both these models have been proposed to explain the verb deficit in non-fluent patients, but they leave the noun problem in fluent patients unexplained. Presumably, the non-fluent patient's verb difficulty is caused by agrammatism, while the fluent patient's problem with nouns is attributed to some kind of (unrelated) semantic-conceptual deficit which (for unexplained reasons) does not affect verbs to the same extent.

A second problem with the morphological account revolves around the assumption that verbs carry more morphology than nouns. This is a reasonable assumption for languages such as English or Italian, but it runs into problems in Hungarian (where nouns carry at least as many morphological markings as verbs) and Chinese (where there are no inflectional morphemes of any kind on nouns or verbs). Osmán-Sági (1987) has shown that the double dissociation in object and action naming can be observed in Hungarian, and Bates et al. (1991a) have demonstrated an equivalent double dissociation for Chinese. Hence it appears that the double dissociation cannot be explained in terms of the "morphological load' carried by verbs.

The syntactic account could deal with the Hungarian and Chinese data, since all languages have verbs that vary in their logical complexity. However, this model has difficulty accounting for the fact that Broca's aphasics tend to preserve the canonical order of words in their sentence production, which means that (at some level) they are able to fill arguments and assign positions in surface structure (Chen 1993; Tzeng and Chen 1988). In the same vein, Shapiro and Levine (1990) have shown that Broca's aphasics show the normal effects of verb complexity in sentence comprehension, which suggests that they do not have difficulty filling the arguments of a verb. Also, as this paper has pointed out, the verb argument account may explain the Broca's deficit, but it provides no explanation for the opposite profile displayed by fluent patients.

The lexical account has some equally serious flaws. First, as noted by Goodglass (1993), this explanation sounds distressingly like a redescription of the data (e.g. patients cannot produce verbs because they have suffered damage to their oral verb lexicon, others cannot write verbs because they have damage to the graphemic output verb lexicon). Such accounts may ultimately prove to be correct, but it would be useful if they had some independent motivation beyond the deficits that they were designed to explain.

A second, deeper problem for the lexical account revolves around the size and nature of the unit that is stored in a putative verb or noun lexicon (across or 
within modalities). This problem is illustrated particularly well in Chinese. Because Chinese has no inflectional or derivational morphology, it relies heavily on compounding to create complex words (for an extensive discussion, see Bates et al. 1993). In fact the overwhelming majority of Chinese words are composed of two or more sublexical elements. With very few exceptions each of these individual elements has its own meaning (and constituted a free-standing singlemorpheme word in ancient Chinese), and each is expressed as a single syllable in the spoken language and a single character in the written language. When these individual elements enter into a compound, their meaning often undergoes modification, but there are no derivational changes in their physical shape. This contrasts markedly with derivational processes in a language such as English, where complex words are built up using derivational morphemes such as '-ment' in 'government', or '-er' in 'bottle-washer'. There are also no unique ordering principles to distinguish a compound from a phrase. For example, the English compound 'dishwasher' involves a switch in the verb phrase order 'wash the dish', but the corresponding Chinese compound uses the same order in the compound and the phrasal form (i.e. WASH DISH). Compounds formed with two open-class morphemes are common in Chinese, and in many cases the compound itself and the open-class morphemes that it contains belong to different grammatical categories (e.g. VN nouns or $\mathrm{VN}$ verbs). Hence category membership must be assigned at two levels: the whole-word level, and the level of word components. If the respective noun and verb lexicons are stored in separate parts of the brain, where are VN compounds stored? Is a VN verb stored in the verb lexicon, and a VN noun in the noun lexicon? Or is the verb element stored in the verb lexicon, while the noun element is stored somewhere else? Should the lexical account be recast at the sublexical level? At both the lexical and sublexical level? If we also allow for the possibility of modality-specific lexicons, then we have to deal with a very large number of separate lexical stores-a graphemic output sublexical verb store, a graphemic output sublexical noun store, a graphemic output whole-word verb store, and so on, to the point where the Law of Parsimony really has been stretched to its limits.

The same problem can be extended to the semantic-conceptual account. If verbs are more affected in anterior patients because they draw heavily on 'motor meanings', then what should happen to noun compounds that contain a verbal element? Conversely, if nouns are more affected in posterior patients because they draw heavily on 'perceptual meanings', then what consequences follow for verb compounds that contain a nominal element? The semantic-conceptual account has an advantage over the lexical account, insofar as it has some independent motivation (e.g. there are good neuroanatomical reasons why verb meanings might be stored in anterior cortex, in and around the motor strip). But such stores will necessarily proliferate if we need separate representations for lexical and sublexical components.

Two major findings in the Bates et al. (1991a) study of action and object naming in Chinese aphasia speak to this issue. First (as noted above), they found a significant double dissociation between Broca's aphasics and Wernicke's aphasics at the whole-word level (for complex and simple word forms), with Broca's performing better on nouns than verbs while Wernicke's show the opposite configuration. Second, they also found a dissociation between nouns and verbs inside compound words, at the level of component morphemes (i.e. Broca's found it easier to lexicalize the nominal portion of a VN compound, while Wernicke's found it easier to lexicalize the verbal component in the same compound words). Based on the two findings, Bates et al. (1991a) draw the following conclusions.

1. The morphological account has to be rejected because a double dissociation between nouns and verbs is maintained in spite of the lack of grammatical morphology in Chinese.

2. Any lexical account which assumes a single level of lexical representation has to be revised, because it cannot account for the double dissociation observed at the sublexical level (i.e. inside of $\mathrm{VN}$ compounds). However, the following possibilities remain open.

3. A semantic-conceptual account cannot be rejected at this point, although it is clear that such an account must be extended to the meanings of individual components within a compound.

4. It may be possible to entertain a revised lexical account, in which individual components of compound words are listed separately in the lexicon. This is a plausible alternative, but (a) it flies in the face of evidence suggesting that normal Chinese subjects treat high-frequency compounds as whole words (Tzeng 1997; Huang and Hsieh 1989), and (b) it may constitute nothing more than a restatement of the data.

In our view, evidence against the two grammatical accounts is now quite solid, but the other models need to be pursued in more detail. In particular, the sublexical dissociations reported by Bates et al. (1991a) require a further investigation, because (as noted by Zhou et al. (1993) many of the VN compounds used in their original study could be interpreted as verb phrases rather than compound words. If this is true, then the sublexical dissociations reported for Chinese could be explained at the whole-word level (see Bates et al. 1993 , for a number of counterarguments). In the present study, we will try to replicate the findings of Bates et al. (1991a) for VN compound verbs, and extend their findings to other compound types that are not subject to the same word/phrase ambiguity. Before we proceed to 
the experiment, we need to discuss the structure of Chinese compounds in more detail.

\section{Compounds in Chinese}

As noted earlier, Chinese morphology is unique in two ways: its grammatical morphology is extremely simple but its open-class morphology is extremely rich and complex. The paucity of grammatical morphology has been intensively discussed in the literature on Chinese aphasia (see Bates et al. 1991a, Packard 1990, Tzeng et al. 1991). The second property has received less attention in aphasia research. In modern Chinese, $80 \%$ of all words are compounds, comprising two or more components (single-syllable morphemes) (Chao 1968, Li and Thompson 1981, Ren 1980). Each stem carries its own meaning and grammatical category. For example, the nominal compound 'penguin' is composed of one verbal component 'qi' (means to stand) and a nominal component 'er' (means goose). Like the nominal compound 'penguin', the verbal compound 'to eat' is made up of two parts: a verbal part 'chi' (means to eat) and a nominal part 'fan' (means cooked rice). Thus, there are situations that a noun may contain a verbal component and a verb may bear a nominal component.

However, not all compounds are uncontroversially words. Verbal compounds such as 'chi-fan' (literally eat-rice, to eat) can also be interpreted as a verb phrase (which means 'to eat rice'). Thus, the component 'chi' (to eat) can function either as a word or a component of the verbal compound 'chi-fan' (to eat). In fact, compounds and short phrases are quite similar in Chinese, along a number of dimensions. In some cases, compounds and phrases are identical in their surface structure. In such cases semantic interpretation is the only way to distinguish a compound from a phrase (Bates et al. 1993). The following example cited from Bates et al. (1993) demonstrates that the semantic interpretation determines the form as a compound or a phrase.

$\begin{array}{rll}\text { (1) (a) jin-yu } & \text { gold-fish } & \text { 'goldfish' } \\ \text { (b) jin yu } & \text { gold fish } & \text { 'fish made from gold'. }\end{array}$

Specifically, the referent 'goldfish' in (1a) is derived from the whole compound 'jin-yu', referring to a special kind of fish. In contrast, the morpheme ' $y u$ ' in (1b) refers to an independent entity, namely 'fish made from gold'. The two are identical at a superficial level, but the existence of a phrasal reading cannot be used to deny existence of the compound reading. Additional evidence of some kind is needed to distinguish between the two.

In some cases, grammatical words are used to distinguish compounds from short phrases. Nominal compounds and relative clauses are the most common pairs of this sort (Chen and Shi 1992, Zhu 1981). For example, the grammatical word 'de' (that) is the way to tell that 'pen-shui-chi' (spring-water-fountain, fountain) is a compound, while 'pen shui de chi-zi' (literally spring water that fountain-DM, the fountain that springs water) is a clause. In cases like this, the structural properties such as the presence of modifier markers 'de' (that) in a clause are important criteria to differentiate compounds from phrases.

Of all the Chinese compounds, the status of verbal VNs is the most controversial, i.e. are they compounds or phrases? This is the case because a VN phrase and its corresponding VN compound are identical in their surface structure. Their semantic interpretations are also very similar in many cases. For example, the phrase 'chi-fan' and the compound 'chi-fan' do not differ in their forms, and their semantic interpretations differ in a very subtle way. Specifically, the noun 'rice' is generic (or without semantic significance) in a compound reading, so 'chi-fan' is interpreted as 'to eat' or 'to have a meal' (not necessary rice), while the same 'rice' in a phrase is interpretation as a referential item (rice), so 'chi-fan' is interpreted as 'to eat rice'. The reason why verbal VNs can function as compounds is that the $\mathrm{VN}$ form is one of the major devices for action naming, and the presence of nouns in verbal $\mathrm{VN}$ compounds is to fulfill a structural requirement for verbal compounds. This morphological process is shown in the following example: When the picture of 'sewing a generic piece of clothing' (instead of sewing clothes) was presented, normal Chinese-speaking subjects invariably produce 'feng-yi-fu' (literally sewclothes-clothes, to sew) rather than a single verb 'feng' (literally sew).

The above three cases demonstrated that compounds and phrases are intimately related. This special relation may trigger phrases to influence the processing on their corresponding compounds out of context. If this is true it is necessary to find more evidence to support the claim that the problem with components take place at the sublexical level. The study by Bates et al. (1991a) was based on VN forms which can have both a phrasal and a compound reading (although most of their items have a very high likelihood of occurring as compounds). In the present study we will also include uncontroversial nominal compounds which can carry only compound readings. The most interesting of these alternative forms are the nominal VN compounds, which are identical to verbal VN in their surface form.

There are four major nominal compound types (where 'major' means that these types are high in frequency): VN, NN, VNN, and NNN types. Examples of each type can be found in (2) through (6).
Nominal compounds
(2) NN lan-hua
(3) $\mathrm{VN}$ qi-er
(4) NNN yu-mao-qiu
$\begin{array}{cc}\text { orchid-flower } & \text { 'orchid' } \\ \text { stand-goose } & \text { 'penguin' } \\ \text { feather-fur-ball } & \text { 'badminton' }\end{array}$
(5) VNN xi-yi-ji
wash-clothes-machine 'washing machine'

Verbal VN compound and phrase
(6) (a) chi-fan eat-rice 'to eat, to have a meal'
b. chi fan eat rice 
Unlike verbal VN compounds (see example 6), which can also be interpreted as a phrase, these four nominal compounds only lend themselves to compound readings (i.e. they cannot be interpreted as verb phrases). Thus, they should provide a further test for sublexical as well as lexical dissociations between nouns and verbs in Chinese.

Performance by aphasic patients on these VN forms can also be compared with other compound types, in particular, VN versus $\mathrm{NN}$ and VNN versus NNN. Each pair contains two word types which differ in the noun/verb status of the first component. For instance, NN and VN differ in that their first components are noun and verb respectively; the same is true for NNN and VNN. By comparing Broca's aphasics with Wernicke's aphasics in the production of specific components within these compound types, we can provide further evidence for (or against) the proposed sublexical dissociation in aphasia. In addition to their utility in exploring the existence of sublexical dissociations, nominal VNs also provide a strong test of the syntactic account, because this type of compound does not always follow the principles that govern verb-argument relationships at the sentence level. For example, argument selection in nominal VN compounds does not reflect the case assignment hierarchy. According to Fillmore's case grammar (Fillmore 1968), case selection must occur in the following order: an object has to be selected before an agent, which has to be selected before an instrument or a location. In direct contrast with this hierarchy, the nominal component of a Chinese VN nominal compound can be an agent (e.g. jizhe, literally record-person, 'journalist') without an object, an instrument (qing-tie, literally invite-card, 'invitation card') without an agent or an object, or a location (kao-xiang, literally roast-box, 'oven') without an object or an agent. Another difference between verb elements in a nominal VN compound and verbs at the sentence level lies at the functional level. In particular the verbal component of a nominal VN compound behaves like the modifier of the noun component; it does not behave like a verb with a single argument. For example, the verbal component 'qing' (to invite) in the compound 'qing- tie' (invite-card) is to tell that the function of the card is to invite 'someone' to come. The argument 'card' is not an obligatory argument of the verb 'to invite'. Instead, the object (e.g. someone), which does not appear in the compound, is the first argument for the verb 'to invite' to select. These two properties of a verbal component in a compound (i.e. lack of the case hierarchy and modifier functions) suggest that verbal components in nominal VN compounds are not functioning like a syntactic verb (i.e. it does not determine its arguments (nouns). Hence any differences that we find between Broca's and Wernicke's aphasics in the production of verb elements in VN nominal compounds cannot be attributed to the syntactic complexity or syntactic role of verbs.
Finally, while we were focusing on the issue of the noun-verb contrast, we also noticed that these four nominal compounds interact with another major factor in Chinese word formation, the frequency of compound types (Huang 1992; Dictionary of Frequency of Modern Chinese Words, Beijing Language Institute 1985). Two-morpheme compounds are by far the most common word order type overall. Indeed, it has been argued that Chinese is rapidly evolving toward a situation in which all (or almost all) open-class words contain at least two morphemes, including some with 'dummy' elements like the affix 'zi' added to maintain a bisyllabic rhythmic pattern (Chao 1968; Li and Thompson 1981; Wang (1958). Chen et al. (1992) have shown that differences in word type frequency affect performance by aphasic patients in word production tasks. Fluent and non-fluent patients both tend to give their best performance on bisyllabic words; they both tend to omit one of the elements in trisyllabic words, and sometimes add an extra element on monosyllabic word targets. Hence there is reason to expect these baseline differences in type frequency to influence performance in the naming task presented below. There are also marked differences in word type frequency within some of the bisyllabic types. Among words that are nouns at the whole-word level, nounnoun compounds (NN) are the most common, followed by N-zi (a single noun plus an affix). For words that are verbs at the whole-word level, VN compounds are very common. Putting these facts together we realize that verbal VN compounds like 'chi-fan' ('to eat', literally 'eat rice') are far more frequent in the language than nominal VN compounds like 'qi-er' (penguin, literally 'stand-goose'). These differences in base-rate difficulty may influence performance on the two VN compound types, preventing a truly symmetrical test of the noun-verb double dissociation at either the wholeword or the sublexical level. For this reason, ancillary information about other compound types (NN, NNN, VNN) will be very useful.

\section{Method}

\section{Subjects}

Subjects for this experiment were 10 Broca's aphasics, 10 Wernicke's aphasics, and nine controls, roughly matched with sex, age, and education. All aphasics were inpatients or outpatients at National Veterans Hospital, the Taiwan University Hospital, or the TriMilitary General Hospital in Taipei. Controls were selected in an informal interview. These normal controls showed intact speech, language and cognitive abilities. All subjects were native speakers of Mandarin (some subjects were also able to speak Taiwanese or Hakka). Appendix A summarizes demographic and neurological information for each subject in the study. Aphasic subjects were classified mainly according to a modified Chinese version of the Boston Diagnostic 
Aphasia Examination (BDAE). Additional inclusionary and exclusionary criteria outlined by Bates and her collaborators (see the papers in Brain and Language, 41, 1991) were also used to assist in subject classification. ${ }^{1}$ Patients were classified as Broca's aphasics if they met the following definition: reduced fluency and phrase length and a tendency toward omission of function words-relative to normals in the Chinese language. Likewise, patients were classified as Wernicke's aphasics if they fitted the following defi-nition: fluent or hyperfluent expressive language, the fluency should be accompanied by marked word-finding difficulties, semantic paraphasia, together with clinical evidence of an impairment in language comprehension.

\section{Materials}

The entire experiment comprises six word types. Five of them are compounds. They are nominal NN compounds, nominal VN compounds, verbal VN compounds, nominal VNN compounds, and nominal NNN compounds. The only non-compound word type is the nominal $\mathrm{N}$ structure, which is not discussed in the present study (cf. Chen et al. 1992). The compounds used here are all classical compounds, taken from Chao (1968), Li and Thompson (1981) and two Mandarin Chinese dictionaries (Liu et al. 1975, Lu 1984). There are 28 nominal VN compounds, 33 verbal VN compounds, $62 \mathrm{NN}$ compounds, $22 \mathrm{VNN}$ compounds, and 20 NNN compounds in the experiment. Each item is depicted in one picture. Pictures used in the experiment were adopted from commercial catalogues in Taiwan or drawn by a Taiwanese. None of the test items was unfamiliar to Taiwanese subjects in the study. Appendix B provides all the testing items in six word types with their English translation.

\section{Testing procedure}

Before the experiment, subjects were given the naming test used in BDAE. Aphasic patients were selected as subjects if they named at least three items correctly. Then we moved on to our experiment, which includes object naming and action naming. Subjects were instructed by the following words:

Xian-sheng (or xiao-jie, tai-tai): qing ni gao-su wo tu-pian li dong- xi (dong-zuo) de ming cheng.

Mr(or Miss, Mrs: I will show you some pictures; you tell me the name of the object (or the action) in the picture.

Two kinds of cues were allowed in the naming test. First, if the subject was distracted by a non-target item

\footnotetext{
${ }^{1}$ We departed from the Bates, Chen et al. criteria in one respect: whereas Bates, Chen et al. require that all patients be at least 3 months post onset, we tested some patients who were within 1-3 months from their stroke. This compromise was necessary because of practical restrictions on hospitalization time and availability of subjects in Taiwan.
}

in the testing picture the tester would point to the target. For example, the picture of 'vase' is a vase with flowers in it. If the subject gives 'flower' instead of 'vase', the tester will point to the vase and ask the subject the name of the object 'vase'. Second, if the subject was not sure which action was named, the tester would perform the action without any verbal cue. For example, the picture of 'raising-hand' is a boy who raises his left hand with his mouth open. If the subject gives a name like 'smile' or 'talking', the tester will perform a 'hand-raising' action and ask the subject the name of the action demonstrated by the tester.

\section{Data analysis}

Items were classified as 'lexically correct' if the target word or an acceptable synonym in the same word class was produced (i.e. a synonym which is also a noun on noun targets; a synonym which is also a verb on verb targets). Note that acceptable synonyms did not have to correspond to the same compound type as the target. For example, one of the items in the NN category was designed to elicit the word 'lan-hua' (orchid-flower). However, responses on this item were scored as lexically correct if the speaker produced 'lan-hua' (the expected NN), 'hua' (flower, a lone $\mathrm{N}$ ) or 'hu-die-lan' (butterfly-butterfly-orchid, an NNN compound referring to a common type of orchid in Chinese culture). These responses differ in their semantic specificity (from a generic flower to a specific butterfly orchid), but they are all acceptable responses for normal adult speakers of Chinese. Thus, items were scored as 'lexically incorrect' if they were not in the expected grammatical category (nouns for verbs; verbs for nouns), or if they were not acceptable synonyms, or if they belonged to the categories 'total omission' or 'uninterpretable jargon'.

Following the criteria of Bates et al. (1991a), items were classified as 'grammatically correct' or 'lexicalized at the whole-word level' if the subject's response was in the same grammatical category as the targetwhether or not that response is not an acceptable synonym. Thus, if the subject gave a verbal VN 'zhufan' (literally cook-rice, 'to cook') or a single verbal V 'chi' (to eat) for the verbal target 'chao-cai' (literally fry-vegetable, 'to fry'), in both cases, a grammatically correct verb lexicalization was credited. However, if the subject responded to the same verbal target (namely chao-cai 'to fry') with a nominal response such as 'fan' (rice) or 'guo-zi' (wok-AFFIX, 'wok'), the response was scored as grammatically incorrect. Unlexicalized or grammatically incorrect items also included the categories 'total omission' and 'unintelligible jargon', which of course cannot be assigned to any grammatical category.

Components were scored as 'lexicalized at the sublexical level' if the components had the same grammatical category as the components of the target (again, the lexicalized element did not have to be identical with 
the target component). Following this criterion, if a subject responds to 'chi-fan' (eat-rice) with another VN 'he-shui' (literally drink-water), then both the verbal component 'he' (to drink) and the nominal component 'shui' (water) are credited as lexicalized elements. Alternatively, if the subject responds 'chi-fan' (literally eat-rice) with a NN compound 'shu-cai' (literally vegetable-vegetable), only the nominal element 'fan' (rice) is credited as a lexicalized component (because 'fan' (rice) and 'cai' (vegetable) are identical with their grammatical category). The verbal component 'chi' (eat) is not credited because the subject did not produce a verbal component. Thus, unlexicalized components refer to the components which differ from target components in the grammatical category. In addition, 'omissions' and 'unintelligible jargon', which cannot be assigned with any grammatical category, are also unlexicalized responses at the sublexical level.

We also classified responses on each target type into one of ten possible whole-word classes, to investigate the interaction between baseline word type biases and performance on the various compound items. The ten word types include six noun types at the wholeword level (VN, NN, VNN, NNN, VVN, and N), and four verb types at the whole-word level (VN, VV, VNN, and V). Thus, word types are distinguished by their grammatical category as whole words as well as the grammatical category of their components. For any given item, the whole word produced (not including false starts or repetitions) was classified into one of these ten categories. Examples of the six nominal word types are given in $7 \mathrm{a}-\mathrm{f},{ }^{2}$ and examples of the four verbal times are given in $8 \mathrm{a}-\mathrm{d}$.

7) Nominal types
(a) VN fei-er
(b) NN xiang-yan
fly-goose
'flying goose'
(c) VNN da-zi-ji hit-character-machine
'typewriter'
(d) NNN yu-mao-qiu feather-fur-ball 'badminton'
(e) VVN ji-suan-ji count-count-machine
(f) $\mathrm{N}$ hua flower 'flower'

8) Verbal types

$\begin{array}{llll}\text { (a) VN } & \text { shui-jiao } & \text { sleep-sleep } & \text { 'to sleep' } \\ \text { (b) VV } & \text { shui-zhao } & \text { sleep-finish 'to fall asleep' } \\ \text { (c) VNN } & \text { tang-tou-fa } & \text { perm-head-hair 'to perm' } \\ \text { (d) V } & \text { chang } & \text { sing } & \text { 'to sing' }\end{array}$

\section{Results}

We will begin with analyses of $\mathrm{VN}$ verbal and $\mathrm{VN}$ nominal compounds, at both the whole-word level and the sublexical level. These analyses will determine

${ }^{2}$ The $\mathrm{N}$ in $(7 \mathrm{f})$ can function as a free word or a word component. However, there are some Ns, which never stand alone as a word, e.g. tie (card) always serves as a component of a word such as qing-tie (invite-card, meaning 'invitation card' and tie-zi (card-affix), meaning also 'invitation card'). whether the effects reported by Bates et al. (1991a) are replicated in the present study. In addition, because VN verbal compounds are subject to the word/phrase criticism (Zhou et al. 1993; Bates et al. 1993), while VN nominal compounds are not, a comparison of the two types will test the generality of the double dissociation that Bates et al. (1991a) reported at the sublexical level. After comparing these two compound types for percent correct (i.e. production of the target) and percent grammatically correct (i.e. production of some kind of noun for a noun target, some kind of verb for a verb target, at both the lexical and sublexical levels), we will then examine the range of word types that normal and aphasic speakers actually produce (correct and incorrect) in response to $\mathrm{VN}$ compounds (both verbal and nominal). This will provide further evidence of a 'noun bias' in Broca's aphasics and a 'verb bias' in Wernicke's. Finally, we will conduct similar analyses over three additional noun compound types: NN (62 items), NNN (20 items) and VNN (22 items). None of these is subject to the phrasal criticism that has been leveled against VN verbs, and all of them provide further evidence for differential noun and verb biases in the two aphasic groups.

\section{Verbal and nominal VN compounds}

\section{Whole-word level}

On the 33 verbal VN items, normal controls produced the target form or an acceptable synonym from the same word class $97.9 \%$ of the time (mean $=32.3$ out of 33). This contrasts with $43 \%$ correct in Broca's aphasics $($ mean $=14.2)$ and $31.2 \%$ correct in Wernicke's aphasics $($ mean $=10.3)$. Hence, even though these VN compounds are verbs at the whole-word level, Broca's seem to produce the target response or an acceptable synonym more often than Wernicke's. When these scores were subjected to a simple one-way analysis of variance across all three groups, the result was highly reliable $F(2,28)=82.25, p<0.0001)$. However, an analysis comparing Broca's and Wernicke's directly just missed significance $(F(1,18)=3.39, p<0.09)$.

On the 28 nominal VN items, normal controls produced the target form or an acceptable synonym $95.6 \%$ of the time $($ mean $=26.8)$, compared with $43.6 \%$ for Broca's (mean $=12.2)$ and a mere $16.1 \%$ for Wernicke's $($ mean $=4.5)$. A one-way analysis of variance across groups was highly reliable $(F(2,28)=125.19, p<$ $0.0001)$, and this time the comparison between Broca's and Wernicke's also reached significance $(F(1,18)=$ 21.86, $p<0.0001)$. We then compared the two VN compound types directly in a 2 (Broca versus Wernicke) $\times 2$ (compound type) multivariate analysis of variance, using percent correct as the dependent variable to equate for the difference in number of items on the two compound types. This analysis determines whether there is indeed a double dissociation between Broca's and Wernicke's aphasics on these two word 
types, at the whole-word level. There was a significant main effect of group $(F(1,18)=12.40, p<0.002)$, reflecting worse performance overall by the Wernicke's aphasics. There was also a significant main effect of type $(F(1,18)=7.91, p<0.012)$, indicating that nominal VN compounds are more difficult across the board. Finally, there was a reliable interaction of group and type $(F(1,18)=9.13, p<0.007)$, suggesting that there is indeed a double dissociation between $\mathrm{VN}$ nouns and $\mathrm{VN}$ verbs at the whole-word level. However, because of the greater across-the-board difficulty of the VN nominal items, this is not a full cross-over interaction (see Figure 1). In fact, separate comparisons within the groups showed that the difference between VN nouns and VN verbs did reach significance for Wernicke's $(F(1,9)=28.14, p<0.0001)$ but not for Broca's $(F(1,9)$ $=0.02$, n.s.).

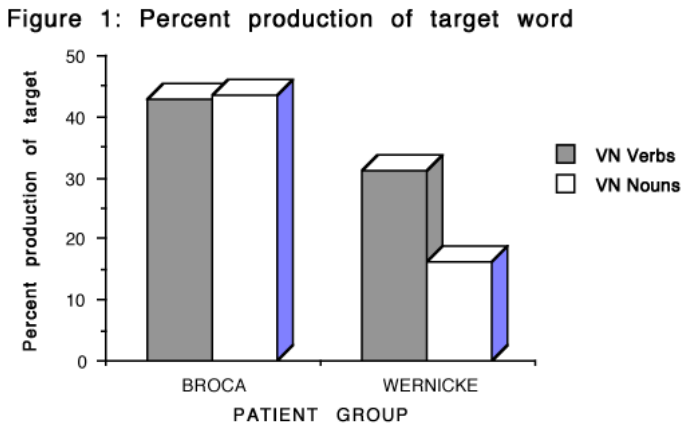

Examination of the cell means suggests that, although normals are close to ceiling, they also have a harder time with VN nominal compounds, compared with VN verbs. However, a one-way MANOVA comparing the two word types within the normal control group failed to reach significance, although there was a trend in this direction $(F(1,8)=2.90, p<0.13)$. We will return to this point later in our examination of substitution types used on different nominal compounds.

We also looked at the kinds of errors produced by the respective aphasia groups, comparing omissions (full or partial) and substitutions (full and partial) on the two compound types. Overall, it is clear that both aphasic groups err more often by substitution than omission (Broca's, mean omissions $=10$, mean substitutions $=19.7$; Wernicke's, mean omissions $=8$, mean substitutions $=29.8$ ). A group (Broca's versus Wernicke's) by error type (omissions versus substitutions) MANOVA was conducted on these error scores. There was a main effect of group $(F(1,18)=6.62, p<$ 0.02 ), confirming worse performance overall by the fluent aphasics. There was a main effect of type $(F(1,18)=50.63, p<0.0001)$, indicating that substitutions are more likely than omissions for both groups. But there was also a significant group by error type interaction $(F(1,18)=7.47, p<0.02)$. Additional com- parisons indicated that Broca's and Wernicke's do not differ in number of omissions, but Wernicke's produce substantially more substitutions $(F(1,18)=10.18, p<$ $0.01)$. Hence the large group difference in number of errors is coming primarily from the category of substitution errors.

These last analyses make it clear that Wernicke's are at a major disadvantage when we use a stringent criterion for 'percentage lexically correct'. One of the main things that we want to know here is whether the two aphasic groups differ in their ability to produce a form that is at least grammatically correct, i.e. whether they can produce (lexicalize) a word that belongs to the same form class as the target (a verb for a verb target; a

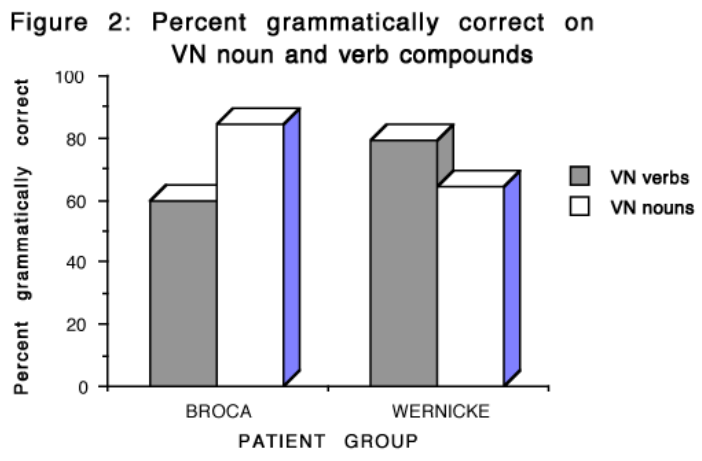

noun for a noun target).

Results using this dependent variable were quite illuminating. For normal controls, nouns were produced on VN noun targets $99.6 \%$ of the time, and verbs were produced on VN verb targets $99.0 \%$ of the time. This of course constitutes nothing more than a proof that our stimuli were successful. For Broca's aphasics, some kind of noun was produced on VN nominal targets $84.3 \%$ of the time, while a verb of some kind was produced on VN verbal targets only $59.7 \%$ of the time. For Wernicke's aphasics, nouns were produced for VN nominal targets $63.6 \%$ of the time while verbs were produced for $\mathrm{VN}$ verbal targets at a mean rate of $79.7 \%$. As illustrated in Figure 2, this appears to constitute a full cross-over dissociation at the wholeword level. In fact, a group (Broca's versus Wernicke's) by type (VN nouns versus VN verbs) multivariate analysis of variance yielded no significant main effect of group $(F(1,18)=0.00$, n.s. $)$ or type $(F(1,18)=$ 1.93 , n.s.), but there was a highly reliable group by type interaction $(F(1,19)=20.72, p<0.0001)$. Furthermore a series of additional analyses confirmed that this is a true cross-over interaction. In production of nouns on a VN noun target, Broca's were significantly better than Wernicke's $(F(1,19)=11.05, p<0.004)$ and significantly worse than normals $(F(1,18)=12.21, p<0.003)$. In production of verbs on a VN verb target, Broca's were significantly worse than Wernicke's $(F(1,19)=$ 6.85, $p<0.02)$ and also significantly worse than normals $(F(1,18)=56.39, p<0.0001)$. Wernicke's 
were worse than normals on both word types (for VN nouns, $F(1,18)=53.05, p<0.0001$; for VN verbs, $F(1,18)=24.82, p<0.0001)$. Within the Broca group, a separate MANOVA comparing the two target types showed that nouns were lexicalized successfully more often than verbs $(F(1,9)=13.65, p<0.005)$; a corresponding MANOVA within the Wernicke's group showed that verbs were produced successfully more often than nouns $(F(1,9)=7.08, p<0.03)$. In short, when we look at production of the target form class rather than production of the target word, then we find a strong double dissociation between Broca's and Wernicke's aphasics in the predicted direction. In view of the fact the VN noun and VN verb compounds are identical in surface form, this is a very interesting confirmation of the noun-verb dissociation in these two aphasic groups.

\section{Sublexical level}

Following Bates et al. (1991a), we focused here on whether the speaker was able to lexicalize the verb and/or the noun element in each VN compound. Credit was given for production of a verb or noun component whether or not the target component was produced (i.e. whether or not it was the 'right' form). Hence this is a sublexical variant of the above analysis of 'grammatically correct at the whole-word level'.

Starting with VN verbs (the same class of items studied by Bates et al. 1991a), mean lexicalization rates for the nominal element were $100 \%$ for normal controls, $90 \%$ for Broca's, and $70.9 \%$ for Wernicke's. A simple one-way analysis of variance over all three groups was significant $(F(2,28)=21.79, p<0.0001)$. All of the two-way comparisons were also reliable (Broca's versus Wernicke's, $F(1,19)=13.11, p<0.001$; Broca's versus normals, $F(1,18)=25.72, p<0.002$; Wernicke's versus normals, $F(1,18)=31.13, p<$ $0.0001)$. On the same VN verb compounds, mean lexicalization rates for the verbal element were $99.3 \%$ for normals, $65.5 \%$ for Broca's, and $79.7 \%$ for Wernicke's. The one-way analysis of variance over all 3 groups again reached significance $(F(2,28)=17.71, p<$ .0001 ), as did all of the two-way comparisons (Broca's versus Wernicke's, $F(1,19)=4.57, p<0.05$; Broca's versus normals, $F(1,18)=39.31, p<0.0001$; Wernicke's versus normals, $F(1,18)=18.60, p<0.0001)$.

To test for the predicted double dissociation, we also compared the two sublexical components directly in a $2 \times 2$ MANOVA (group by sublexical element). There was no main effect of group $(F(1,19)=0.25$, n.s.), which means that the two groups were equally successful (or unsuccessful). There was a significant main effect of type $(F(1,19)=4.87, p<0.04)$, reflecting greater difficulty overall on the verbal element in a VN compound. Most important for our purposes here, there was a significant group by type interaction $(F(1,19)=$ 21.79, $p<0.0001)$, confirming that there is indeed a double dissociation at the sublexical level for $\mathrm{VN}$ verbal compounds, illustrated in Figure 3(a). This finding constitutes a clear replication of Bates et al. (1991a), with different subjects and different materials.

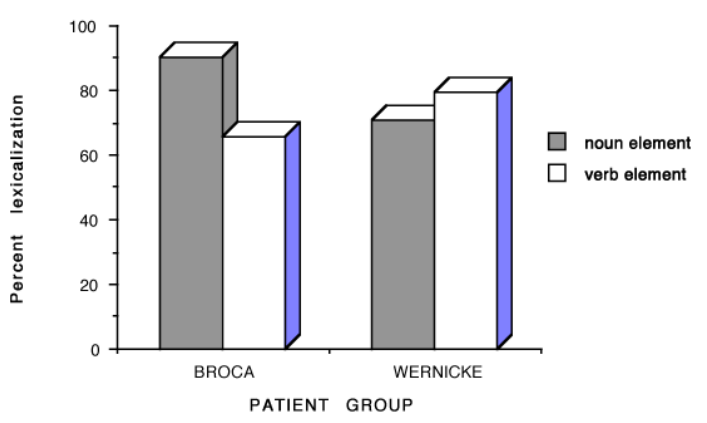

Figure 3 (a): Lexicalization of the noun vs. verb elements of $\mathrm{VN}$ verbal compounds.

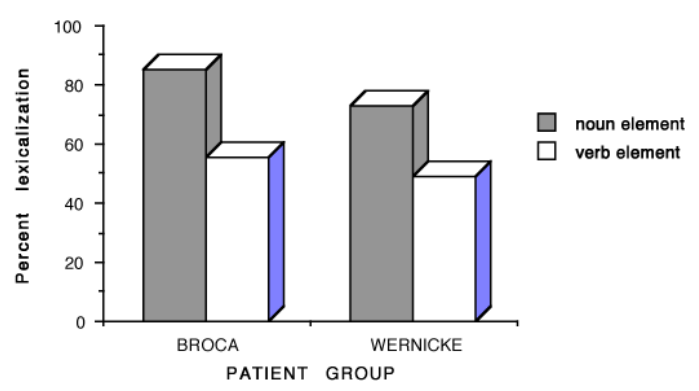

Figure 3 (b): Lexicalization of the noun vs. verb elements of VN nominal compounds.

Turning now to the nominal VN compounds, success rates for lexicalization of the nominal element were $100 \%$ for normal controls, $85.4 \%$ for Broca's, and $73.2 \%$ for Wernicke's. In a simple analysis of variance over all three groups the main effect of group was reliable $(F(2,28)=10.71, p<0.0001)$. In addition, two-way comparisons showed that each of the aphasic groups was significantly worse than normal controls (Broca versus normal, $F(1,18)=16.73, p<0.001$; Wernicke's versus normal, $F(1,18)=18.68, p<0.001)$. However, the difference between the two aphasic groups just missed significance $(F(1,19)=3.22, p<$ $0.09)$. On the verbal element of nominal VN compounds the success rates were $91.7 \%$ for normal controls, $55.7 \%$ for Broca's and $49.3 \%$ for Wernicke's. The analysis of variance across all three groups did reach significance $(F(2,28)=28.99, p<0.001)$, and each of the aphasic groups was worse than normal controls (Broca's versus normal, $F(1,18)=49.64, p<$ 0.001; Wernicke's versus normal, $F(1,18)=59.81, p<$ 0.001). However, the difference between Broca's and Wernicke's did not even approach significance $(F(1,19)$ $=0.88$, n.s.). It is obvious that nominal VN compounds 
do not yield the same kind of sublexical dissociation that we observed for verbal VN items.

To confirm this impression, we carried out a $2 \times 2$ (group by sublexical element) MANOVA, on Broca's and Wernicke's only. There was no main effect of group $(F(1,19)=2.82$, n.s. $)$, indicating that both groups are equally impaired on these items at the sublexical level. There was a large and reliable main effect of type $(F(1,19)=45.59, p<0.0001)$, indicating that all subjects have a harder time lexicalizing the verbal piece in a nominal VN compound. The group by type interaction did not even approach significance $(F(1,19)$ $=0.52$, n.s.). Finally, we conducted individual MANOVAs within the respective Broca and Wernicke's groups, comparing the verb versus the noun element in nominal VN compounds. In both groups, the subjects had a harder time producing the verbal unit (Broca's, $F(1,9)=38.25, p<0.0001$; Wernicke's, $F(1,9)$ $=14.32, p<0.004)$. Although the sublexical interaction for $\mathrm{VN}$ nouns is not significant, it is shown in Figure 3(b) for comparison with Figure 3(a), i.e. the sublexical interaction for $\mathrm{VN}$ verbs.

To summarize so far, despite the strong evidence for a double dissociation at the whole-word level for VN verbal compounds compared with VN nominal compounds, the two compound types are not comparable at the sublexical level. On VN verbal compounds, we replicate the sublexical dissociations reported by Bates et al. (1991a), but on VN nominal compounds, the same dissociation is not observed. At first glance this appears to provide support for the criticism raised by Zhou et al. (1993), who claim that the sublexical dissociation reported in our earlier work actually reflects the phrasal nature of verbal $\mathrm{VN}$ items, and hence constitutes nothing more than a by-product of the syntactic problem experienced by Broca's aphasics. However, there are two aspects of our findings that mitigate against this interpretation.

First, there appear to be differences between the two compound types in baseline difficulty, reflected in the fact that normal controls are also less likely to lexicalize the verb component in a VN nominal compound (i.e. $91.7 \%$ for the verb morpheme versus $100 \%$ for the noun morpheme). To determine whether this apparent difference is statistically significant we carried out a MANOVA comparing noun and verb elements on VN nominals, for normals only. The difference was highly reliable $(F(1,8)=32.67, p<0.0001)$.

Second, the Broca's aphasics behave quite consistently across the two compound types: that is, they always have a harder time lexicalizing the verbal element, independent of grammatical class at the whole-word level. This means that (a) the deficit in verb lexicalization that Broca's aphasics show at the sublexical level is not simply an artifact of the phrasal status of some VN verbs (against Zhou et al. 1993), and (b) the disappearance of the double dissociation on nominal VN items comes entirely from the Wernicke's aphasics. These fluent patients had a harder time producing nominal elements on verbal VN compounds (as we would predict), but they also had a harder time producing the verbal element on nominal VN compounds (exactly the opposite of what we would predict). This suggests that the absence of a double dissociation at the sublexical level on VN nominals may be due to baseline differences in item difficulty that affect performance in all three groups, but have a particularly severe impact on Wernicke's aphasics.

By examining the word types that subjects produced as alternatives to the VN targets, we can determine whether performance was influenced by high-frequency competitors that 'attract' responses in a particular direction at the lexical and/or sublexical level. We can also obtain additional evidence that Broca's aphasics dislike words with a 'verb piece', while Wernicke's aphasics gravitate toward words with verbal elements.

\section{Alternative word types}

We have proposed that VN nominals may not show the expected double dissociation at the sublexical level because these compounds differ from $\mathrm{VN}$ verbals in base-rate difficulty. That is, normals also find it hard to lexicalize the verb element in a VN noun compound. We suggested at the outset that performance on this task may be affected by differences in the frequency of particular compound types. Among words that are verbs at the whole-word level, VN compounds are a very frequent word type. However, among words that are nouns at the whole-word level, VN compounds are far less frequent; the most common noun compounds are NN or Nzi. Table 1 summarizes all of the word types that patients and controls produced in response to VN nominal and verbal compounds. Although no single category predominates, it is clear that patterns of substitution differ for the two target forms. It is also clear that Broca's aphasics exhibit a consistent 'noun bias' and Wernicke's continue to show a 'verb bias' at this relatively fine-grained level of analysis.

First, consider the alternatives produced on VN nominals. As we suspected, normal controls make almost all of their substitutions from the high-frequency NN category (mean $=2.33$ per subject, approximately $8 \%$ of all responses). This helps to explain why there are base-rate differences in production of the $\mathrm{V}$ element in VN nominals. The NN response was also quite common for Broca's (mean $=4.9,17.5 \%$ of all responses) and for Wernicke's (mean $=4.7,16.8 \%$ of all responses). When we compare use of this highfrequency alternative across the three subject groups, we find that both patient groups produce NN more than normal controls (Broca's, $F(1,18)=12.37, p<0.003$; Wernicke's, $F(1,18)=4.89, p<0.05)$, but Broca's and Wernicke's do not differ from one another $(F(1,19)=$ 0.03 , n.s.). We may conclude that competition from the high-frequency NN alternative occurs for all normal 
and patient groups, obscuring the predicted double dissociation at the sublexical level.

We also looked at production of a lone $\mathrm{V}$ versus a lone $\mathrm{N}$ in response to $\mathrm{VN}$ nominal compounds. For normal controls, there was only one example of a lone $\mathrm{N}$, and no examples of a lone $\mathrm{V}$. By contrast, both alternatives appeared among the aphasics, but at different rates. For Broca's, a lone nominal element N was produced $13.6 \%$ of the time, while a lone verbal element $\mathrm{V}$ occurred $1.4 \%$ of the time. For Wernicke's, a lone $\mathrm{N}$ was produced $5.7 \%$ of the time, while a lone $\mathrm{V}$ occurred in $4.6 \%$ of all responses. A $2 \times 2$ MANOVA was conducted comparing lone $\mathrm{N}$ versus lone $\mathrm{V}$ for Broca's and Wernicke's only. There was no main effect of group $(F(1,19)=1.40$, n.s. $)$, but there was a significant effect of type $(F(1,19)=7.68, p<0.013)$, indicating the greater prevalence of single-noun responses on these VN nominal compounds. Most important for our purposes here, there was a significant group by type interaction $(F(1,19)=5.39, p<.032)$. Hence the double dissociation between Broca's and Wernicke's is reliable, in the predicted direction.

Of all the substitution types in Table 1 for $\mathrm{VN}$ nominals, the most interesting alternative may be the production of $\mathrm{VV}$ compounds in place of a $\mathrm{VN}$ noun. These items are particularly interesting for our purposes here, because they are 'verbs all the way down', in response to targets that are nouns at the whole-word level, with one nominal element at the sublexical level. There were no responses in the VV category for normal controls. The mean for Broca's aphasics was 0.2 (representing well under $1 \%$ of all responses), while the mean for Wernicke's was 1.3 (constituting $4.6 \%$ of all responses). Although these alternatives were not very frequent overall, the difference between Broca's and Wernicke's is significant $(F(1,19)=6.15, p<.023)$, providing further evidence for a 'verb bias' in Wernicke's aphasics.

Turning now to the VN verbal items, we found very few substitutions of any kind for normal controls. They produced NN responses here only $1 \%$ of the time, compared with $8.3 \%$ for $\mathrm{VN}$ nominal targets. Of course this is not surprising, since the target in this case is a verb instead of a noun at the whole-word level. The only other substitution observed for normal controls in this category was VV compounds $(1.3 \%$ of all responses to VN verbal targets). This confirms our suggestion that $\mathrm{VN}$ nominals differ from $\mathrm{VN}$ verbs because the former experience competition from the high-frequency NN word type, while the latter do not. By contrast, Broca's aphasics produced a relatively large number of $\mathrm{NN}$ responses to $\mathrm{VN}$ verbal targets (mean $=6.0,18.2 \%)$; these responses also occurred in Wer-nicke's, but they were less frequent $($ mean $=2.3$, $7 \%)$. The difference between aphasic groups was significant $(F(1,19)=6.22, p<0.023)$.

We also looked again at the production of a single $\mathrm{V}$ or a single $\mathrm{N}$. These responses did not occur at all among normal controls. For Broca's a lone $\mathrm{N}$ was produced $9.6 \%$ of the time, while single $\mathrm{V}$ elements constituted $2.1 \%$ of all responses to a verbal VN target. For Wernicke's the corresponding rates were $3.6 \%$ production of a lone $\mathrm{N}$ and $7.9 \%$ production of a lone $\mathrm{V}$. Although these are (again) relatively low-frequency response types, their distribution suggests further evidence for a double dissociation. This impression was verified in a $2 \times 2$ MANOVA (group by $\mathrm{V}$ versus $\mathrm{N}$ response). The analysis yielded no main effect of group $(F(1,19)=0.01$, n.s.) or type $(F(1,19)=0.73$, n.s.), but there was a reliable group by type interaction $(F(1,19)=9.19, p<0.007)$.

Finally, we looked at the production of VV compounds, a somewhat more appropriate alternative for VN verbal targets. As noted, this did occur for normal controls (although it was very rare). For Broca's the VV response occurred $1.8 \%$ of the time, compared with $11.5 \%$ for Wernicke's. This difference was statistically reliable $(F(1,19)=10.24, p<0.005)$. We also carried out a $2 \times 2$ MANOVA, comparing group (Broca versus Wernicke) with NN versus VV responses to $\mathrm{VN}$ verb targets. The two main effects were not significant, but there was (again) a reliable group by type interaction $(F(1,19)=11.94, p<0.003)$, indicating a double dissociation, with more 'double noun' responses in Broca's aphasics and more 'double verb' responses among Wernicke's.

To summarize, the word type analysis helps to clarify the earlier comparison of VN nouns and VN verbs, from several points of view. First, we have confirmed our suspicion that VN nominals are more difficult (even for normal controls) because of competition from the high-frequency NN compound type. This fact makes it difficult to see the same sublexical dissociation that emerged so clearly for VN verbals. Second, we find clear evidence for a noun bias among Broca's, in production of a lone $\mathrm{N}$ and/or production of a double-noun response to either of these compound types. Conversely, Wernicke's aphasics are more likely to produce a lone $\mathrm{V}$ and/or a double-verb response to VN compounds of any kind. We conclude that there is indeed a double dissociation at the sublexical level in Broca's and Wernicke's aphasics. Regardless of the form class of the target word at the whole-word level, Broca's find it hard to lexicalize verbal components, while Wernicke's tend to insert verbal components where they do not belong.

\section{NN, NNN and VNN nominals}

The three additional compound types at issue here are all nouns at the whole-word level, including VNN compounds. Hence they should provide further insights into production of complex word types by Broca's and Wernicke's aphasics. 


\section{Whole-word level}

On the $62 \mathrm{NN}$ compounds items, lexically correct responses (i.e. the intended $\mathrm{NN}$ or an acceptable noun synonym) were produced $95.2 \%$ of the time by normal controls, versus $55.3 \%$ by Broca's and $27.7 \%$ by Wernicke's. An analysis of variance across all three groups did yield a significant main effect $(F(2,28)=$ 73.23, $p<0.0001)$. Both aphasic groups performed more poorly than normals (Broca's, $F(1,18)=61.87, p$ $<0.0001$; Wernicke's, $F(1,18)=197.80, p<0.0001)$. The difference between the two aphasic groups was also significant $(F(1,19)=18.15, p<0.0001)$.

In our analysis of $\mathrm{VN}$ nominals and $\mathrm{VN}$ verbs, double dissociations emerged most clearly when we used a less stringent criterion for correct performance, accepting any response that was grammatically correct (i.e. in the same form class as the target word). Applying the same criterion here, we find that normal controls produced some kind of nominal response to NN targets $97.1 \%$ of the time, compared with $86.9 \%$ for Broca's aphasics and $75.2 \%$ for Wernicke's. The difference across all three groups was reliable $(F(1,28)$ $=8.99, p<0.001)$, and both aphasic groups were significantly worse than normal (Broca's, $F(1,9)=6.93$, $p<0.02$; Wernicke's, $F(1,9)=17.96, p<0.001)$, but the difference between aphasic groups just missed significance $(F(1,19)=3.82, p<0.07)$. In other words the two aphasic groups manage to produce some kind of noun at the whole-word level most of the time, and although there is a tendency for Broca's to succeed more often, the difference is only marginally reliable. When subjects failed to respond with the required noun, they did so for one of two reasons: because they produced a word that is a verb at the whole-word level, or because they produced jargon or failed to respond at all. Obviously if there were differences in rates of jargon and omission, that might skew the results. However, there were no differences between aphasic groups in the percent of trials that fell into this 'unclassifiable' category (Broca's $=22.4 \%$; Wernicke's $=25.3 \% ; F(1,19)=0.25$, n.s.). We looked at the proportion of all responses to $\mathrm{NN}$ items that were verbs at the whole-word level, and found that this category accounted for only $0.4 \%$ of all responses by normals, versus $3.6 \%$ by Broca's aphasics and $15.3 \%$ by Wernicke's. In this case the difference between the two aphasic groups was reliable $(F(1,19)=16.88, p<$ 0.001 ), constituting further evidence that Wernicke's show a verb bias-even on NN items, where there is no verbal element at the lexical or the sublexical level.

On the 20 items designed to elicit NNN compounds, normals produced a lexically correct form (i.e. the target or an acceptable noun synonym) $97.8 \%$ of the time, compared with $43 \%$ for Broca's and only $16 \%$ for Wernicke's. The analysis over all three groups reached significance $(F(2,28)=72.33, p<0.0001)$, both aphasic groups were significantly worse than normal (Broca's,
$F(1,18)=52.35, p<0.0001$; Wernicke's $(F(1,18)=$ 400.23, $p<0.0001)$, and the difference between the aphasic groups was also reliable $(F(1,19)=11.41, p<$ $0.003)$. If we use the less stringent criterion of 'grammatically correct', then normals produce some kind of noun at the whole-word level $100 \%$ of the time in response to NNN targets, compared with $81.5 \%$ for Broca's and $74 \%$ for Wernicke's. In this case the difference between the two aphasic groups does not reach significance $(F(1,19)=0.78$, n.s. $)$, even though Broca's appear to be somewhat more successful. However, when we look at the production of verb alternatives in response to NNN targets, a group difference emerges once again. Verb production at the wholeword level is uncommon for Broca's on these NNN items (3.5\% of all responses), but Wernicke's produce some kind of a verb at the whole-word level $22.5 \%$ of the time. The difference between Broca's and Wernicke's is reliable $(F(1,19)=14.34, p<0.001)$, providing still more evidence for the verb bias in Wernicke's aphasics. Once again there was no reliable difference between the two groups in jargon or omission $(F(1,19)=3.83, p<0.07)$, although Broca's appear to be worse off on these items (15\% jargon or omission, versus $3.5 \%$ for Wernicke's).

The most complex types employed in the present study were VNN compounds, which also function as nouns at the whole-word level. Using the more stringent criterion of percent lexically correct (i.e. production of the target word or an acceptable noun synonym), success rates for normals were $97.5 \%$, compared with only $23.6 \%$ for Broca's, and $13.2 \%$ for Wernicke's. All group comparisons were reliably different: across the three groups $(F(2,28)=292.22, p<$ $0.0001)$; Broca's versus normals $(F(1,18)=712.53, p<$ $0.03)$; Wernicke's versus normals $(F(1,18)=468.40, p$ $<0.0001)$, and Broca's versus Wernicke's $(F(1,19)=$ $5.91, p<0.03)$. It is clear that these items pose a substantial challenge for both groups of aphasic patients. When we use the less stringent criterion of percentage grammatically correct (i.e. production of some kind of a noun at the whole-word level on nominal VNN compounds), the success rates were $99.5 \%$ for normals $($ mean $=21.9), 70.9 \%$ for Broca's $($ mean $=15.6)$ and $54.1 \%$ for Wernicke's $($ mean $=11.9)$. Hence performance is much better for all three groups using this standard. In this case the difference between Broca's and Wernicke's is also reliable $(F(1,19)=4.75$, $p<0.05)$.

Recall that responses were scored as 'grammatically incorrect' if they were in the wrong form class, or if they were total omissions or uninterpretable jargon. To clarify the nature of the failures experienced by Broca's and Wernicke's aphasics on VNN compounds, we carried out an additional analysis restricted to production of words that are verbs at the whole-word level. Such responses were observed only $0.5 \%$ of the 
time in normal controls, but both aphasic groups produced verbs relatively often on these items, i.e. $15.9 \%$ in Broca's and $24.1 \%$ in Wernicke's. In contrast with our analyses of the two compound types that have no verbal element (i.e. NN and $\mathrm{NNN}$ ), the difference between Broca's and Wernicke's missed significance for VNN targets $(F(1,19)=2.63, p<0.13)$. There was (again) no difference between Broca's and Wernicke's aphasics in the jargon/omission category $(F(1,19)=$ 1.39 , n.s.).

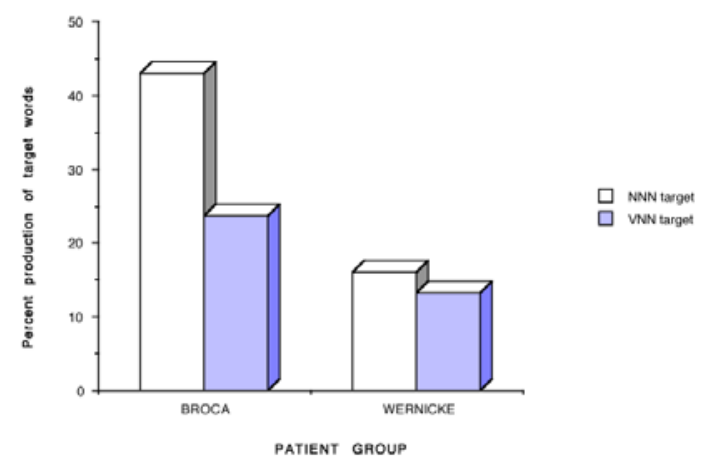

Figure 4: Percent production of target on NNN and VNN nominal compounds.

The contrast between NNN and VNN nominal compounds is of particular interest here. Both item types are nouns at the whole-word level, both are quite long and complex, and both are relatively infrequent compound types (compared with VN nouns, VN verbs and NN nominal compounds). However, the NNN items are compatible at both levels (i.e. they are "nouns all the way down') while the VNN items require one verbal element. If our arguments about doubledissociations at the sublexical level are correct, then we should find that Broca's have more difficulty with VNN than NNN, while Wernicke's should have trouble with both sets. The cell means cited above provide support for this view, but to test it further we conducted a MANOVA on percent lexically correct, comparing groups (Broca's versus Wernicke's) and item types (VNN versus NNN). Results included a significant main effect of type $(F(1,18)=9.01, p<0.01)$, due to the greater overall difficulty of VNN, together with a significant main effect of group $(F(1,18)=12.74, p<$ $0.002)$, indicating worse performance overall by Wernicke's. Most important for our purposes here, there was a significant interaction between group and item type $(F(1,18)=5.01, p<0.04)$, in the predicted direction. To confirm this interpretation we also conducted separate MANOVAs for each of the two aphasic groups. For Broca's aphasics production of a lexically acceptable response was significantly more likely on NNN than VNN $(F(1,9)=8.73, p<0.02)$. For Wernicke's there was no difference in the overall difficulty of these two item types $(F(1,9)=0.68$, n.s. $)$. These results are presented in Figure 4.

In the same vein we carried out a MANOVA comparing VNN and NNN compounds in the production of a response that is grammatically correct (i.e. some kind of noun at the whole-word level). In this analysis there was a main effect of item type $(F(1,18)=$ $17.06, p<0.001)$, reflecting the greater overall difficulty of VNN items. However, the main effect of group was not reliable $(F(1,18)=2.74, p<0.12)$, and there was no significant interaction $(F(1,18)=1.59$, n.s.). So the problem lies not with 'noun-ness per se', but with the relative difficulty that Broca's aphasics experience in producing a lexically correct form in response to VNN items. It appears that the mere presence of a verbal element within a nominal VNN compound poses a special challenge for Broca's aphasics, reducing their performance well below the levels observed on NNN or NN. Because the VNN items are true compounds, and in no way subject to the verb phrase criticism raised by Zhou et al., we take this as further evidence for a double dissociation between nouns and verbs at the sublexical level. Conversely, all of these data provide further evidence for a verb bias in Wernicke's aphasics. Even though the NN, NNN and VNN compounds are all classified as nouns at the whole-word level, Wernicke's aphasics frequently respond by producing verbs. This tendency will become clearer still as we move to analysis of the alternative word types that are produced in response to these complex nouns.

\section{Alternative word types}

Sublexical analyses were fairly straightforward for VN nouns and VN verbs, because there are only two possible slots within each target word, and they lie in a clear, complementary distribution. By contrast it is difficult to conduct an analysis of omissions or substitutions at the sublexical level for NN, NNN and VNN compounds, since it is difficult to assign a relationship between the 'intended unit' and the 'observed unit'. For example, if the patient produces a lone $\mathrm{V}$ in response to an NN target, how should that response be classified? Which $\mathrm{N}$ element was omitted, and which was substituted? Given these problems, questions about 'noun intrusions' and 'verb intrusions' at the sublexical level are best addressed by looking at the competing forms produced by normals and aphasic patients in response to these complex noun targets.

Table 2 summarizes the alternative word types produced by normals and aphasics in response to NN, NNN and VNN compounds. At the whole-word level we already know that Wernicke's patients tend to produce a pathological number of verbs in response to these nominal targets. Examination of Table 2 tells us more about the sublexical structure of their substitutions. 
For normal controls, substitutions are relatively rare overall, as we have already noted. Normals produced a form with the target structure $88.4 \%$ of the time on $\mathrm{NN}$ items, $87.2 \%$ on NNN, and $84.4 \%$ on VNN. Among the correct synonyms or incorrect substitutions that they did produce, most were nouns at the wholeword level (see Table 2). Looking at the internal structure of substitutions, normals produced words containing some kind of $\mathrm{V}$ element $3.2 \%$ of the time on $\mathrm{NN}$ targets, $1.1 \%$ of the time on NNN targets, versus $8.7 \%$ on VNN targets. So although substitutions are rare in normals, there does appear to be some effort to include the verbal piece on items designed to elicit a VNN nominal response. In fact, if we look at the data in terms of percentage of all substitutions (as opposed to percentage of all correct and incorrect responses), we find that alternatives containing a verbal element account for $3 \%$ of all substitutions by normals on $\mathrm{NN}$ items, $11 \%$ of substitutions on NNN items, compared with $59 \%$ of all substitutions on VNN. This baseline fact will be relevant to our interpretation of the aphasia data.

For Broca's aphasics, substitutions are more common overall, and (as we saw earlier) they tend to be nouns at the whole-word level. Looking at the internal structure of word substitutions (see Table 2), we can see that substitutions containing a verbal element account for $4.7 \%$ of all responses by Broca's aphasics on $\mathrm{NN}$ targets, $5 \%$ of all responses on NNN targets, but $20.5 \%$ of all responses on VNN targets. If we look at this pattern expressed as a percentage of all substitutions (as opposed to a percentage of all responses, correct or incorrect), we find that Broca's produce substitutions with an internal verb $22 \%$ of the time on NN items, $12 \%$ on NNN items, versus $38 \%$ on VNN targets. This is quite similar to the pattern displayed by normals. In fact, three separate two-way analyses comparing Broca's with normals on each target type (using percentage of all substitutions with a verbal element as the dependent variable) yielded no significant differences.

As we have already seen, Wernicke's produce more word substitutions than any other group, and they are also more likely to produce intrusions that are verbs at the whole-word level. Looking at the internal structure of their word substitutions (see Table 2), we can see that Wernicke's produce substitutions containing some kind of verbal element $14.8 \%$ of the time on NN targets, $29.5 \%$ on NNN targets, and $29.3 \%$ on VNN targets. Expressed as a percentage of all substitutions within each category, the corresponding figures are $45 \%$ on NN, $38 \%$ on NNN and $47 \%$ on VNN. Overall, these ratios appear to be higher for Wernicke's aphasics than they are for normals or for Broca's aphasics. We carried out separate two-way comparisons looking at the percentage of all substitutions containing a verbal element, first comparing Wernicke's with Broca's and then comparing Wernicke's with normals. In the Wernicke/Broca comparisons, there were significant differences in the ratio of substitutions with an internal verb on NN targets $(F(1,19)=8.14, p<0.02)$, and on NNN targets $(F(1,19)=11.31, p<0.003)$, but the comparison on VNN targets failed to reach significance $(F(1,19)=1.54$, n.s. $)$. In the Wernicke/normal comparisons, the difference just missed significance on NN $(F(1,18)=3.98, p<0.07)$, was reliable on NNN items $(F(1,18)=7.53, p<0.02)$ but did not reach significance on VNN targets $(F(1,18)=2.59$, n.s. $)$.

Putting these lines of evidence together, we may conclude that Wernicke's produce a high ratio of substitutions that contain a verbal element of some kind, a tendency that is most striking on $\mathrm{NN}$ and $\mathrm{NNN}$ targets that are 'nouns all the way down'. Broca's produce relatively few verb intrusions, although it seems that they do struggle to produce some kind of verb piece in response to VNN nominal compoundsas though, at some level, they are trying to match the desired pattern. Normals produce very few substitutions of any kind, but when they do, their responses are closer to those of Broca's aphasics.

\section{Summary and conclusion}

Although our results vary somewhat depending on the compound type in question, they provide further evidence for a double dissociation between non-fluent Broca's aphasics and fluent Wernicke's aphasics in the production of nouns and verbs. Furthermore, this dissociation appears to hold at both the lexical and sublexical level, providing a serious challenge to several alternative accounts of this peculiar double dissociation.

First, our results for VN verbal compounds replicate those of Bates et al. (1991a) in every respect, with different materials and different subjects. This includes a replication of their sublexical effects, i.e. Broca's have more trouble producing the verbal element within the VN compound, while Wernicke's have a harder time producing the nominal element. However, like the original findings by Bates et al. (1991a), this result is potentially controversial, because there is so much uncertainty within Chinese linguistics concerning the status of VN verbal compounds. Are they true compounds? Or are they actually functioning as a verb phrase, i.e. a main verb with a nominal argument? If the latter interpretation is correct, then this supposed sublexical effect may be nothing more than a restatement of our findings at the whole-word level (i.e. Broca's find it hard to lexicalize main verbs, while Wernicke's have a harder time with lexicalization of whole nouns). To disambiguate between these alternative interpretations, we included an array of alternative compound types in the present study, including VN compounds that function as nouns at the wholeword level (and are therefore not subject to the verb phrase criticism), as well as NN, NNN and VNN compounds that are all nouns at the whole-word level. 
On the VN nominals, results were somewhat different from those for VN verbs. On the one hand, analyses directly comparing VN nouns with VN verbs provide further evidence for a double dissociation at the whole-word level (i.e. Broca's show their worst performance on VN verbs while Wernicke's have a harder time with VN nouns). This is a particularly interesting finding, because the two item types are superficially very similar. However, we did not find the same double dissociation at the sublexical level on VN nominals. In fact, all subjects (including normal controls) had a harder time lexicalizing the 'verb piece' within such items. At first glance this appears to provide support for Zhou et al.'s contention that the sublexical effects reported by Bates et al. (1991a) are an artifact of the verb phrase confound. However, we believe that several additional facts mitigate against this view. First, Broca's aphasics were quite consistent across the two item types, i.e. they always found it more difficult to lexicalize the verbal element within a VN compound. It is the Wernicke's who failed to show a consistent pattern across the two compound types.

Second, a detailed analysis of the alternative word order types showed that all subjects (including normal controls) have a tendency to replace VN nominals (a relatively infrequent word order type) with NN nominals (a very frequent word order type). This fact makes it difficult to compare VN verbs and VN nouns directly at the sublexical level. The strongest evidence for a double dissociation at the sublexical level comes from the other substitutions produced by Broca's and Wernicke's aphasics on these two compound types. In particular, Wernicke's have an across-the-board tendency to produce verbal elements (e.g. a lone V, or a VV), a tendency that is far less common in the non-fluent patients. These patterns were verified in our analyses of NN, NNN and VNN compounds. All three compound types function as nominals at the whole-word level. However, on all three we found that Wernicke's aphasics tend to replace nouns with verbs at the whole-word level, and to replace nominal elements with verbal elements at the sublexical level (including lone V, VV and VVN). These patterns are far less common among Broca's aphasics, who tend instead to substitute one kind of noun for another.

The strong bias toward production of verbs in Wernicke's aphasia appears to be a robust phenomenon. This part of the double dissociation has often been ignored, with theorists focusing instead on the problem that Broca's aphasics experience in the production of main verbs. As we noted in the introduction, the morphological account and the syntactic account both view the main-verb problem in Broca's aphasia as a byproduct of agrammatism, while offering no explanation at all for the 'noun avoidance' or 'verb attraction' displayed by some fluent patients. The lexical account and the semantic-conceptual account do deal with both sides of the equation, and may be compatible with our findings at the whole-word level. However, as we pointed out earlier, these accounts have difficulty with our findings at the sublexical level, where they appear to be unparsimonious if not completely circular.

Do we have anything better to offer? Without question, our results require an explanation at both the lexical and the sublexical level. ${ }^{3}$ Indeed, the two levels appear to interact in a number of interesting ways (e.g. all subjects including normals are 'pulled' toward the high-frequency $\mathrm{NN}$ type in items that require a VN noun, but they do not show the same tendency on VN verbs). This suggests that we need an account that captures a combination of lexical and sublexical facts. We cannot, for example, simply replace a whole-word theory (e.g. whole nouns are stored in posterior cortex while whole verbs are stored toward the front) with a purely compositional theory (e.g. noun morphemes are stored in posterior cortex while verb morphemes are stored toward the front, with all compound words created 'on-line'). We certainly do not have a complete theory to offer. However, it is worth noting that lexical and sublexical effects can be handled together in connectionist theories of language, where whole words are stored as distributed representations with a permeable internal structure, at both the level of form and the level of meaning (Plunkett and Marchman 1991, 1993, MacWhinney 1987, 1991, Seidenberg and McClelland 1989, Elman and McClelland 1986, Bates et al. 1991b). In these models the subcomponents of a complex word can be activated together or separately, depending on the context, and there are many examples in which effects are observed at both levels of analysis (e.g. in studies of the acquisition and generalization of past-tense morphemes during the course of whole-word learning). A number of investigators have recently pointed out the advantages of connectionist models with distributed representations in accounting for the symptoms displayed by brain-damaged patients (Hinton and Shallice 1991, Marchman 1993, Plaut 1994, 1997, Martin et al. 1994, Schwartz et al. 1994, Seidenberg and McClelland 1989). It is possible that such models could be extended to account for the interesting pattern of dissociations displayed by Chinese Broca's and Wernicke's aphasics in the production of compound nouns and verbs.

\footnotetext{
${ }^{3}$ Just as an English speaker might say 'D like in dog', using lexical information to clarify a phonological ambiguity, Chinese speakers often use a compound word in which a single morpheme participates to clarify the ambiguity inherent in many single Chinese words or syllables. For example, the syllable 'ji' has several different meanings, each represented by a different character. To disambiguate, a speaker might say 'ji' as in 'fei-ji', indicating 'ji' as in 'airplane' (literally fly-machine), instead of 'ji' as in 'huo-ji' ('turkey', literally fire-chicken). This common phenomenon provides anecdotal evidence in favour of the idea that lexical and sublexical structure are simultaneously available to Chinese speakers, to different degrees depending on the context).
} 


\section{Acknowledgements}

The research described was conducted as part of an unpublished dissertation by Sylvia Chen, Department of Linguistics, University of Southern California. We are grateful to Zhong Yu-Mei, Li Shu-Er and Liao Qiu-Mei at Taipei Veterans' Hospital, Hsieh Fu-Mei, Zheng Jing-Qiu, and Chen Hsin-Ping at National Taiwan University Hospital, and Chen Hsiu-Fang and Lin LiYing at Tri-Military General Hospital for their assistance in data collection in Taiwan. We also thank Dr. Lien Yi-Nan for generously giving support to our research in Taiwan. Finally, special thanks are given to Meiti Opie for her help in finishing the paper. Partial support for this research was provided by a grant to Elizabeth Bates, 'Cross-linguistic studies in aphasia'NIH/NIDCD Grant 2-R01-DC00216-10.

\section{References}

Bates, E., Friederici, A., Wulfeck, B. and Juarez, L. (1988). On the preservation of word order in aphasia. Brain and Language, 33, 323-364.

Bates, E., Chen, S., Tzeng, O., Li, P. and Opie, M. (1991a). The noun-verb problem in Chinese aphasia. Brain and Language, 41, 203-233.

Bates, E., Chen, S., Li, P., Opie, M. and Tzeng, O. (1993). Where is the boundary between compounds and phrases in Chinese? A reply to Zhou et al. Brain and Language, 45, 94-107.

Bates, E., Thal, D. and Marchman, V. (1991). Symbols and syntax: A Darwinian approach to language development. In N. Krasnegor, D. Rumbaugh, R. Schiefelbusch and M. Studdert-Kennedy (Eds.), Biological and Behavioral Determinants of Language Development. Hillsdale, NJ: Erlbaum.

Berndt, R. and Zingeser, L. (1991). Grammatical class effects in word production: Finding the locus of the deficit. Brain and Language, 41, 597-600.

Caplan, D. (1987). Neurolinguistics and Linguistic Aphasiology: An Introduction. Cambridge/New York: Cambridge University Press.

Caramazza, A. and Berndt, R. (1985). A multicomponent view of agrammatic Broca's aphasia. In M.-L. Kean (Ed.), Agrammatism. Orlando: Academic Press.

Caramazza, A. and Hillis, A. (1991). Lexical organization of nouns and verbs in the brain. Nature, 346, 269.

Chao, Y. R. (1968). A Grammar of Spoken Chinese. University of California Press, Berkeley, California.

Chen, S. (1993). On grammatical deficits in Chinese aphasia. In F. R. Eckman (Ed.), Confluence: Linguistics, L2 Acquisition, and Speech Pathology. Amsterdam/Philadelphia: John Benjamins Publishing Company.
Chen, S., Andersen, E., Kempler, D. and Bates, E. (1992, October). On the structure preservation in Chinese aphasia. Paper presented at the Academy of Aphasia, Toronto, Canada.

Chen, S. and Shi, D. X. (1992). On the feeding relation between syntax and morphology: Evidence from Chinese nominal V-N compounds. In H. S. Wang and F. Tsao (Eds.), Proceedings of the Third Internal Symposium on Chinese Languages and Linguistics, Hsinzhu.

Damasio, A. (1989). Time-locked multiregional retroactivation: A systems-level proposal for the neural substrates of recall and recognition. Cognition, 33, 25-62.

Elman, J. and McClelland, J. (1986). Interactive processes in speech perception: The TRACE model. In D. Rumelhart and J. L. McClelland (Eds.), Parallel distributed processing: Explorations in the microstructure of cognition. Cambridge, MA: MIT Press.

Fillmore, C.J. (1968). The case for case. In E. Bach and R.T. Harms (Eds.), Universals in Linguistic Theory. New York: Holt, Rinehart \& Winston.

Glosser, G., Saykin, A.J., Sperling, M.R. and O'Connor, M.J. (1994). Dissociations between object and action naming following anterior temporal lobectomy. Brain and Language, 47, 546-548.

Goodglass, H. (1993). Understanding Aphasia. San Diego: Academic Press.

Hillis, A. and Caramazza, A. (1994). Lexical organization of the brain. (Report \#43). Baltimore, MD: The Johns Hopkins University, Cognitive Neuropsychology Laboratory.

Hinton, G. E. and Shallice, T. (1991). Lesioning a connectionist network: Investigations of acquired dyslexia. Psychological Review, 98, 74-95.

Huang, S-F. (1992). Lexical innovation and semantic change. Paper presented at the Third Symposium on Chinese Languages and Linguistics, Hsinzhu.

Huang, S-F. and Hsieh, M.L. (1989). Acquisition and comprehension of Mandarin compound morphology. Paper presented at the International Conference on Syntax Acquisition in the Chinese Context. Hong Kong.

Institute of Language Teaching and Research. (1985). Xiandai Hanyu Pinlu Cidian (A Frequency Dictionary of Modern Chinese). Beijing: Beijing Language Institute Press.

Joanette, Y. and Brownell, H.H. (Eds.). (1990). Discourse Ability and Brain Damage: Theoretical and Empirical Perspectives. New York : SpringerVerlag.

Lapointe, J.S. (1985). A theory of verb form use in the speech of agrammatic aphasics. Brain and Language, 24, 100-155. 
Li, C.N. and Thompson, S.A. (1981). Mandarin Chinese: A Functional Reference to Chinese Grammar. Berkeley: University of California Press.

Liu, Y. M., Zhuang, Z. R. and Wang, S. Z. 1975. Frequency Count of 40,000 Chinese Words. Taipei: Lucky Publisher.

Lu, S. C. (Ed.). (1984). Ci-hui (A Collection of Chinese words). Taipei: Wen-hua Tu-shu Gongsi (Culture Books Inc.)

MacWhinney, B. (1987). The competition model. In B. MacWhinney (Ed.), Mechanisms of Language Acquisition (pp. 249-308). Hillsdale, NJ: Erlbaum.

MacWhinney, B. (1991). Connectionism as a framework for language acquisition theory. In $\mathrm{J}$. Miller (Ed.), Research on Child Language Disorders: A Decade of Progress (pp. 3-22). Austin, TX: Pro-Ed.

Marchman, V. (1993). Constraints on plasticity in a connectionist model of the English past tense. Journal of Cognitive Neuroscience, 5, 215-234.

Martin, N., Dell, G.S., Saffran, E.M. and Schwartz, M.F. (1994) Origins of paraphasias in deep dysphasia: Testing the consequences of a decay impairment to an interactive spreading activation model of lexical retrieval. Brain and Language, 47, 52-88.

Miceli, G., Silveri, M., Villa, G. and Caramazza, A. (1984). On the basis for agrammatics' difficulty in producing main verbs. Cortex, 20, 207-220.

Miceli, G., Silveri, C., Nocentini, U. and Caramazza, A. (1988). Patterns of dissociation in comprehension and production of nouns and verbs. Aphasiology, 2, 351-358.

Mitchum, C. and Berndt, R. (in press). Verb retrieval and sentence construction: Effects of targeted intervention. In G. W. Humphreys and J. M. Riddoch (Eds.), Cognitive Neuropsychology and Cognitive Rehabilitation. London: Erlbaum.

Osmán-Sági, J. (1987). Action naming in Hungarian aphasic patients. Abstracts of the Second World Congress of Neuroscience IBRO. [Neuroscience, Supplement to Vol. 22, p.S509.]

Packard, J. (1990). Agrammatism in Chinese: A case study. In L. Menn and L. Obler (Eds.), Agrammatic Aphasia: Cross-language Narrative Sourcebook (pp. 1191-1221). Amsterdam: Benjamins.

Petersen, S., Posner, M., Fox, P., Mintun, M. and Raichle, M. (1988). Positron emission tomographic studies of the cortical anatomy of single-word processing. Nature, 331, 585-589.

Plaut, D.C. (1994). Parallel distributed processing challenges the strong modularity hypothesis, not the locality assumption. Behavioral and Brain Sciences, 17(1), 77-78.
Plaut, D.C. (1995). Double dissociation without modularity: Evidence from connectionist neuropsychology. Journal of Clinical and Experimental Neuropsychology, 17, 291-321.

Plunkett, K. and Marchman, V. (1991). U-shaped learning and frequency effects in a multi-layered perceptron: Implications for child language acquisition. Cognition, 38, 43-102.

Plunkett, K. and Marchman, V. (1993). From rote learning to system building: Acquiring verb morphology in children and connectionist nets. Cognition, 48, 21-69.

Ren, X. L. (1980). Hanyu Gouchixue (Chinese morphology). Shanghai: The Commercial Publisher.

Saffran, E., Schwartz, M. and Marin, O. (1980). The word order problem in agrammatism. II. Production. Brain and Language, 10, 263-280.

Schwartz, M.F., Saffran, E.M., Bloch, D. and Dell, G.S. (1994). Disordered speech production in aphasic and normal speakers. Brain and Language, 47, 5288.

Seidenberg, M. and McClelland, J. (1989). A distributed developmental model of visual word recognition and naming. Psychological Review, 96, 523-568.

Shapiro, L. and Levine, B. (1990). Verb processing during sentence comprehension in aphasia. Brain and Language, 38, 21-47.

Tzeng, O. (1997). On-line processing of Chinese compounds: Evidence from lexical decision. Manuscript in preparation, University of California, Riverside.

Tzeng O. and Chen, S. (1988). Aphasia in Chinese. Symposium on Aphasia in Non-European Languages. Academy of Aphasia, Montreal, October.

Tzeng, O., Chen, S. and Hung, D. (1991). The classifier problem in Chinese aphasia. Brain and Language, 41, 184-202.

Wang, L. (1958). Hanyu Shigao (History of the Chinese language). Beijing: Kexue Chubanshe (Science Publisher).

Zhou, X. L., Ostrin, R. K. and Tyler, L. K. (1993). The noun-verb problem and Chinese aphasia: Comments on Bates et al. (1991). Brain and Language, 45, 86-93.

Zhu, D. X. (1981). Yufa Jiangyi (Chinese Syntax). Shanghai: The Commercial Publisher.

Zingeser, L. and Berndt, R. (1990). Retrieval of nouns and verbs in agrammatism and anomia. Brain and Language, 39, 14-32. 


\section{Appendix A: Subject Information}

ID

No. Age Sex Handedness Post onset Aetiology Lesion

\section{Broca's}

$\begin{array}{ccllcll}2 & 37 & \text { Male } & \text { Right } & \text { 8 years } & \text { Head injury } & \text { Left FTP } \\ 4 & 32 & \text { Male } & \text { Right } & 5 \text { months } & \text { Head injury } & \text { Left frontal lobe } \\ 7 & 37 & \text { Male } & \text { Right } & 4 \text { months } & \text { CVA } & \text { No CT report } \\ 11 & 43 & \text { Male } & \text { Right } & 5 \text { months } & \text { CVA } & \text { No CT report } \\ 21 & 69 & \text { Female } & \text { Right } & 20 \text { years } & \text { CVA } & \text { Left MCA territory } \\ 23 & 36 & \text { Male } & \text { Right } & 5 \text { months } & \text { Head injury } & \text { Left FT; right frontal } \\ 28 & 70 & \text { Male } & \text { Right } & 5 \text { months } & \text { CVA } & \text { Left frontal } \\ 29 & 56 & \text { Female } & \text { Right } & 4 \text { months } & \text { CVA } & \text { Left basal ganglia } \\ 30 & 64 & \text { Male } & \text { Right } & \text { 3 months } & \text { CVA } & \text { Left putamen } \\ 31 & 62 & \text { Male } & \text { Right } & 1 \text { month } & \text { CVA } & \text { Left frontal-parietal }\end{array}$

Wernicke's

$\begin{array}{ccllrll}6 & 47 & \text { Male } & \text { Right } & 3 \text { months } & \text { CVA } & \text { Left lateral ventricle/sulcus } \\ 8 & 59 & \text { Male } & \text { Right } & 14 \text { months } & \text { CVA } & \text { Left temporal } \\ 15 & 54 & \text { Male } & \text { Right } & 3 \text { years } & \text { CVA } & \text { Left basal ganglia } \\ 17 & 62 & \text { Male } & \text { Right } & 2.5 \text { years } & \text { CVA } & \text { Left FTP } \\ 20 & 67 & \text { Male } & \text { Right } & 2.5 \text { years } & \text { CVA } & \text { Left FTP } \\ 22 & 69 & \text { Male } & \text { Right } & 8 \text { months } & \text { Haemorrhage } & \text { Left putamen/ internal capsule } \\ 25 & 68 & \text { Male } & \text { Right } & 10 \text { months } & \text { CVA } & \text { Left temporal } \\ 35 & 62 & \text { Male } & \text { Right } & 2 \text { months } & \text { CVA } & \text { Left lacunar infarction } \\ 36 & 63 & \text { Male } & \text { Right } & 3 \text { months } & \text { CVA } & \text { Left TP } \\ 37 & 47 & \text { Male } & \text { Right } & 1 \text { month } & \text { CVA } & \text { Brainstem, pons }\end{array}$

Normal control

$\begin{array}{llll}38 & 34 & \text { Male } & \text { Right } \\ 39 & 45 & \text { Male } & \text { Right } \\ 40 & 37 & \text { Female } & \text { Right } \\ 41 & 63 & \text { Female } & \text { Right } \\ 42 & 60 & \text { Male } & \text { Right } \\ 43 & 55 & \text { Male } & \text { Right } \\ 44 & 40 & \text { Male } & \text { Right } \\ 45 & 55 & \text { Male } & \text { Right } \\ 46 & 37 & \text { Male } & \text { Right }\end{array}$

CVA = Cerebrovascular accident $; \mathrm{CT}=$ computerized tomography; $\mathrm{FT}=$ fronto-temporal; $\mathrm{FTP}=$ fronto-temporal-parietal; $\mathrm{TP}=$ temporo-parietal. 


\section{Appendix B: Experiment Stimuli}

\section{Verbal VN}

1. jiao-shui

water-water

'to water'

2. tiao-wu

jump-dance

'to dance'

3. tou-qiu

pitch-ball

'to pitch'

4. diao-yu

hook-fish

'to fish'

5. hua-chuan

row-boat

'to row'

6. tang-fa

heat-hair

'to perm'

7. ju-gong

bow-bow

'to bow'

8. kai-deng

open-lamp

'to turn on'

9. qi-chuang

up-bed

'to get up'

10. shui-jiao

sleep-sleep

'to sleep'

11. chang-ge

sing-song

'to sing'

12. xie-zi

write-character

'to write'

13. qi-ma

ride horse

'to ride'

14. xi-zao

wash-bath

'to bathe'

15. tan-qin

play-musical instrument

'to play'

16. chi-fan

eat-rice

'to eat'

17. chao-cai

fry-vegetable

'to stir-fry '

18. zou-lu

walk-road

'to walk'

19. tiao-sheng

jump-rope

'to jump rope'

20. zhao-xiang

shine-photo

'to photograph'

21. tiao-shui

jump-water

'to dive'

22. hua-xue

slide-snow

'to ski'

23. kao-rou

roast-meat

'to roast'

24. hua-zhuang

put on-cosmetics

'to apply make-up' 
25. huai-yun

26. wo-shou

27. you-yong

28. shuo-hua

29. ju-shou

30. dian-huo

32. an-ling

33. wan-yao bear-pregnancy

hold-hand

swim-swim

speak-speech

raise-hand

light-fire

push-bell

bend-waist 'to be pregnant'

'to shake (hands)'

'to swim'

'to speak'

'to raise (hand)'

'to smoke'

'to ring'

'to bow'

\section{VN (Nominal)}

1. suan-pan

2. fei-ji

3. qi-er

4. tiao-qi

5. mo-bu

6. zheng-long

7. yi-sheng

8. tou-shou

9. wan-ju

10. zhi-piao

11. wo-shi

12. zhao-pian

13. fa-piao

14. shui-yi

15. yin-zhang

16. wei-qun count-dish

fly-machine

stand-goose

jump-chess

wipe-rag

steam-cage

cure-man(professional)

pitch-hand

play-instrument

issue-ticket

lie-room

shine-slice

distribute-ticket

sleep-clothes

print-seal

wrap-skirt 'abacus'

'airplane'

'penguin'

'Chinese checkers'

'wiper'

'steamer'

'doctor'

'pitcher'

'toy'

'check'

'bedroom'

'photo'

'invoice'

'pajamas'

'seal'

'apron' 


\begin{tabular}{|c|c|c|}
\hline 17. nao-zhong & alarm-clock & 'alarm clock' \\
\hline 18. qing-tie & invite-card & 'invitation card' \\
\hline 19. bei-zhen & put-needle & 'pin' \\
\hline 20. jian-dao & cut-knife & 'scissors' \\
\hline 21. tuo-xie & pull-shoe & 'slippers' \\
\hline 22. xi-guan & suck-hose & 'straw' \\
\hline 23. chao-fan & fry-rice & 'fry rice' \\
\hline 24. wei-qi & surround-chess & 'Japanese chess; go' \\
\hline 25. yu-gang & bath-tub & 'bathtub' \\
\hline 26. diao-deng & hang-lamp & 'hanging lamp' \\
\hline 27. hu-shi & protect-staff & 'nurse' \\
\hline 28. diao-chuang & hang-bed & 'hammock' \\
\hline
\end{tabular}

\section{NN}

1. dian-hua

tele-speech

'telephone'

2. huo-che

fire-car

'train'

3. $y i-f u$

clothes-clothes

'clothes'

4. bao-zhi

newspaper-paper

'newspaper'

5. qi-che

gas-car

'car'

6. tie-lu

steel-road

'railroad'

7. dian-nao

tele-brain

'computer'

8. tou-fa

head-hair

'hair'

9. chuang-hu

window-window

'window'

10. gang-qin

steel-musical instrument

'piano'

11. dian-ying

tele-shadow

'movie'

12. mao-bi

fur-pen

'brush pen'

13. shu-bao

book-bag

'school bag' 


\begin{tabular}{|c|c|c|}
\hline 14. di-qiu & ground-ball & 'earth' \\
\hline 15. zu-qiu & foot-ball & 'football' \\
\hline 16. er-duo & ear-shape & 'ear' \\
\hline 17. qian-bi & lead-pen & 'pencil' \\
\hline 18. jian-bang & shoulder-shoulder & 'shoulder' \\
\hline 19. huo-cai & cow-milk & 'milk' \\
\hline 22. ya-chi & tooth-tooth & 'tooth' \\
\hline 23. yu-mi & jade-rice & 'corn' \\
\hline 24. ping-guo & apple-fruit & 'apple' \\
\hline 25. yi-ba & tail-tail & 'tail' \\
\hline 26. lan-qiu & basket-ball & 'basketball' \\
\hline 27. xin-zang & heart-organ & 'heart' \\
\hline 28. bang-qiu & stick-ball & 'baseball' \\
\hline 29. mi-feng & honey-bee & 'bee' \\
\hline 30. jiang-you & sauce-oil & 'soybean sauce' \\
\hline 31. nai-fen & milk-powder & 'milk powder' \\
\hline 32. la-zhu & wax-candle & 'candle' \\
\hline 33. mian-bei & cotton-cover & 'comforter' \\
\hline 34. jin-yu & gold-fish & 'goldfish' \\
\hline 35. che-lun & car wheel & 'wheel' \\
\hline 36. qi-shui & gas-water & 'soda' \\
\hline 37. pi-bao & leather-bag & 'bag' \\
\hline 38. yu-yi & rain-clothes & 'raincoat' \\
\hline 39. lan-hua & orchid-flower & 'orchid' \\
\hline 40. cha-ye & tea-leave & 'tea' \\
\hline 41. huo-ji & fire-chicken & 'turkey' \\
\hline 42. mao-yi & fur-clothes & 'sweater' \\
\hline
\end{tabular}




\begin{tabular}{|c|c|c|}
\hline 43. shou-zhuo & hand-bracelet & 'bracelet' \\
\hline 44. mao-xian & fur-thread & 'knitting wool' \\
\hline 45. hua-ping & flower-bottle & 'vase' \\
\hline 46. hai-xing & sea-star & 'sea star' \\
\hline 47. tou-kui & head-helmet & 'helmet' \\
\hline 48. zhu-gan & bamboo-pole & 'bamboo pole' \\
\hline 49. yao-shi & key-key & 'key' \\
\hline 50. you-tong & post-pail & 'mailbox' \\
\hline 51. bei-ke & shell-shell & 'shell' \\
\hline 52. lian-ou & lily-root & 'lily root' \\
\hline 53. bing-gan & cookie-dryness & 'cookie' \\
\hline 54. dan-gao & egg-cake & 'cake' \\
\hline 55. cha-hu & tea-pot & 'teapot' \\
\hline 56. lun-tai & wheel-tire & 'tire' \\
\hline 57. nai-ping & milk-bottle & 'milkbottle' \\
\hline 58. wang-qiu & net-ball & 'tennis' \\
\hline 59. ban-ma & stripe-horse & 'zebra' \\
\hline 60. hua-pen & flower-pot & 'flowerpot' \\
\hline 61. cao-mei & grass-berry & 'strawberry' \\
\hline 62. fan-shu & western-yam & 'yam' \\
\hline
\end{tabular}

\section{NNN}

1. huo-che-zhan

fire-car-station

'train station'

2. mei-gui-hua

rose-rose-flower

'rose'

3. shui-long-tou

water-dragon-head

'faucet'

4. shou-dian-tong

hand-electric-tube

'flashlight'

5. yu-mao-qiu

feather-fur-ball

'badminton' 


\begin{tabular}{|c|c|c|}
\hline 6. shui-guo-dao & water-fruit-knife & 'knife' \\
\hline 7. ma-xi-tuan & horse-show-group & 'circus' \\
\hline 8. xian-ren-zhang & fairy-person-palm & 'cactus' \\
\hline 9. ji-qi-ren & machine-machine-man & 'robot' \\
\hline 10. qian-bi-he & lead-pen-case & 'pen case' \\
\hline 11. jin-yu-gang & gold-fish-tub & 'fish tank' \\
\hline 12. ri-guang-deng & sun-light-lamp & 'fluorescent lamp' \\
\hline 13. mao-tou-ying & cat-head-eagle & 'owl' \\
\hline 14. shen-fen-zheng & body-identity-certificate & 'ID' \\
\hline 15. le-se-tong & trash-trash-pail & 'trash pail' \\
\hline 16. san-jiao-xing & three-angle-shape & 'triangle' \\
\hline 17. ri-ben-ren & sun-root-man & 'Japanese' \\
\hline 18. niu-zai-ku & cow-kid-pant & 'jeans' \\
\hline 19. huo-cai-he & fire-wood-case & 'matchbox' \\
\hline 20. xiang-pi-quan & rubber-skin-circle & 'rubber band' \\
\hline
\end{tabular}

\section{VNN}

1. ji-cheng-che

2. shou-yin-ji

3. hua-zhuang-pin

4. pen-shui-chi

6. xi-fa-jing

7. ji-shi-bu

8. chui-feng-ji

9. xiang-ri-kui

10. you-yong-chi

11. lu-yin-dai

$\begin{array}{ll}\text { count-distance-car } & \text { 'taxi' } \\ \text { receive-sound-machine } & \text { 'radio' } \\ \text { put-cosmetics-product } & \text { 'cosmetics' } \\ \text { spring-water-fountain } & \text { 'camera' } \\ \text { wash-hair-essence } & \text { 'shampoo' } \\ \text { record-event-note } & \text { 'notebook' } \\ \text { blow-wind-machine } & \text { 'hair dryer' } \\ \text { face-sun-sunflower } & \text { 'sunflower' } \\ \text { swim-swim-pool } & \text { 'swimming pool' } \\ \text { record-sound-belt } & \text { 'audio tape' }\end{array}$


12. tiao-se-pan

13. xi-chen-qi

14. da-zi-ji

15. gua-hu-dao

16. you-yong-quan

17. xi-yi-ji

18. pai-qi-guan

19. kai-guan-qi

20. xi-yi-fen

21. feng-yi-ji

22. luo-di-chuang mix-color-dish

suck-dust-instrument

hit-character-machine

shave-mustache-knife

swim-swim-circle

wash-clothes-machine

pass-gas-hose

open-can-instrument

wash-clothes-powder

sew-clothes-machine

fall-ground-window 'palette'

'vacuum cleaner'

'typewriter'

'shaver'

'lifebuoy'

'washing machine'

'muffler'

'can opener'

'detergent'

'sewing machine'

'window' 
Table 1. Word type responses to $\mathrm{VN}-\mathrm{N}$ and $\mathrm{VN}-\mathrm{V}$

\begin{tabular}{lrrrrrr}
\hline & \multicolumn{3}{c}{$\mathbf{V N - N}$} & & \multicolumn{5}{c}{$\mathbf{V N - V}$} \\
& & & & & & \\
\cline { 2 - 7 } & $\mathbf{B}$ & $\mathbf{W}$ & $\mathbf{N}$ & $\mathbf{B}$ & $\mathbf{W}$ & $\mathbf{N}$ \\
$\mathbf{N N}$ & 17.5 & 16.8 & 8.3 & 18.2 & 7.0 & 1.0 \\
$\mathbf{V V}$ & 0.7 & 4.6 & - & 1.8 & 11.5 & 1.3 \\
$\mathbf{N}$ & 13.6 & 5.7 & 0.4 & 9.6 &. .3 .6 & - \\
$\mathbf{V}$ & 1.4 & 4.6 & - & 2.1 & 7.9 & - \\
$\mathbf{V N : N}$ & 47.5 & 27.9 & 91.3 & 5.8 & 1.5 & - \\
$\mathbf{V N : V}$ & 4.3 & 12.9 & - & 54.5 & 58.2 & 97.6 \\
$\mathbf{N}-\mathbf{z i}$ & 3.6 & 7.9 & - & - & - & - \\
$\mathbf{V - z i}$ & --- & 1.4 & - & - & - & - \\
\hline
\end{tabular}


Table 2. Word type responses to NN, NNN and VNN

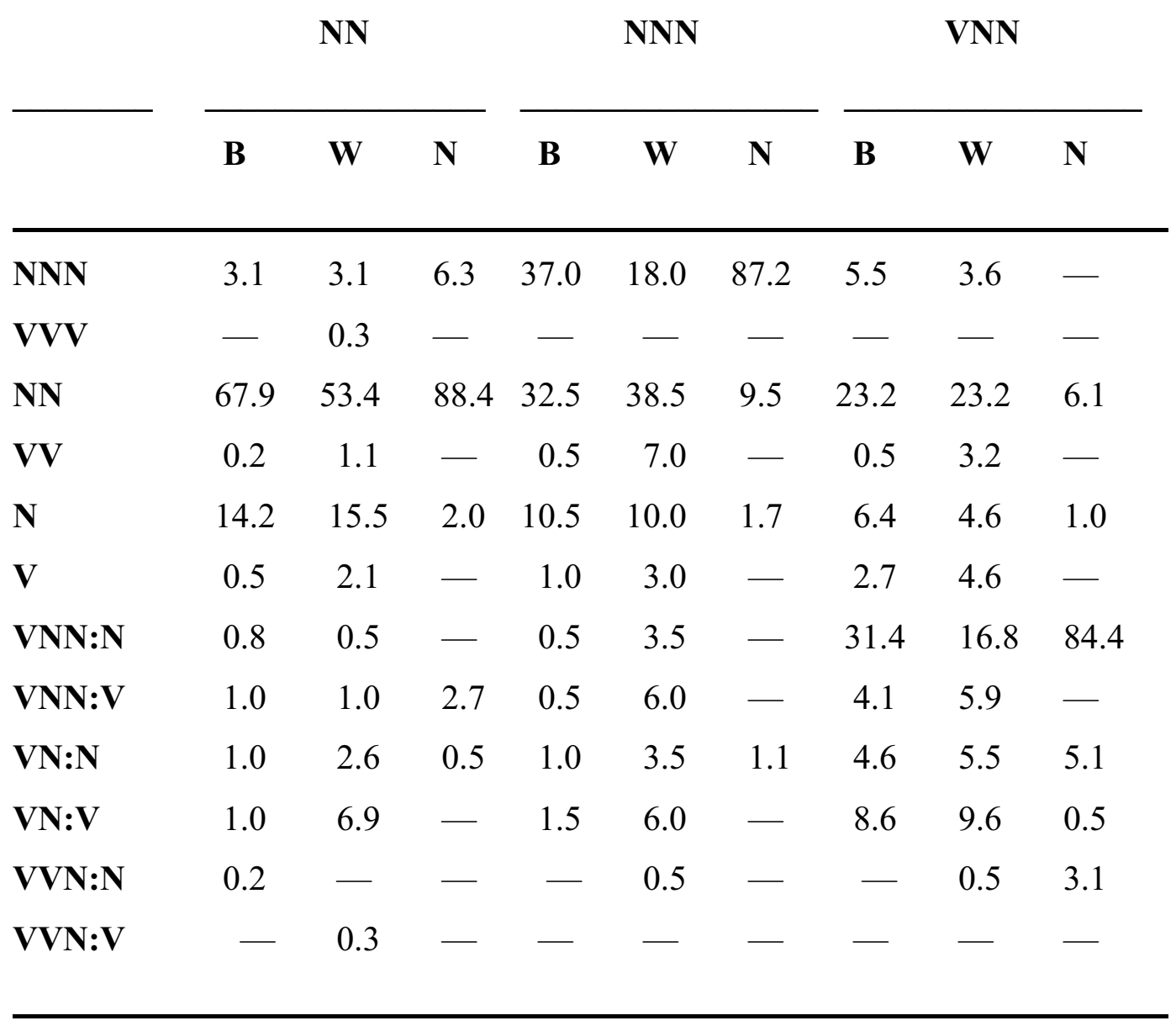

